Florida International University FIU Digital Commons

3-24-2011

\title{
Aggressive Personality: The Use of a New Self- Report Measure Built from Justification Mechanisms
}

Anya T. Edun

Florida International University, anya.edun@gmail.com

DOI: $10.25148 /$ etd.FI1 1050607

Follow this and additional works at: https://digitalcommons.fiu.edu/etd

\section{Recommended Citation}

Edun, Anya T., "Aggressive Personality: The Use of a New Self-Report Measure Built from Justification Mechanisms" (2011). FIU Electronic Theses and Dissertations. 391.

https://digitalcommons.fiu.edu/etd/391 


\section{FLORIDA INTERNATIONAL UNIVERSITY}

Miami, Florida

AGGRESSIVE PERSONALITY: THE USE OF A NEW SELF-REPORT MEASURE BUILT FROM JUSTIFICATION MECHANISMS

A thesis submitted in partial fulfillment of the

requirements for the degree of

MASTER OF SCIENCE

in

PSYCHOLOGY

by

Anya T. Edun

2011 


\section{To: Dean Kenneth Furton}

College of Arts and Sciences

This thesis, written by Anya T. Edun, and entitled Aggressive Personality: The Use of a New Self-Report Measure Built from Justification Mechanisms, having been approved in respect to style and intellectual content, is referred to you for judgment.

We have read this thesis and recommend that it be approved.

Chockalingam Viswesvaran

$\begin{array}{r}\text { Chockalingam Viswesvaran } \\ \hline \text { Victoria Pace } \\ \hline \text { Jesse S. Michel, Major Professor }\end{array}$

Date of Defense: March 24, 2011

The thesis of Anya T. Edun is approved.

\begin{tabular}{r}
$\begin{array}{r}\text { Dean Kenneth Furton } \\
\text { College of Arts and Sciences }\end{array}$ \\
\hline Interim Dean Kevin O'Shea \\
University Graduate School
\end{tabular}

Florida International University, 2011 


\section{DEDICATION}

I dedicate this thesis to my parents, Azam and Anne Edun; sister, Alana Edun; and grandparents, Shakoor and Bonita Manraj (maternal) and Florence Ally (paternal). Without their continual support, words of encouragement, and unconditional love, the completion of this work would not have been possible. From the bottom of my heart, thank you! 


\section{ACKNOWLEDGMENTS}

I would like to thank each of my committee members for their encouragement and invaluable contributions to this Thesis. I would especially like to thank my major professor, Dr. Jesse Michel, for his patience, guidance, and willingness to help me meet all of my goals and deadlines. I also want to acknowledge my colleague, Holli Thometz, for her tremendous support with the statistical analysis of this research. 


\section{ABSTRACT OF THE THESIS \\ AGGRESSIVE PERSONALITY: THE USE OF A NEW SELF-REPORT MEASURE BUILT FROM JUSTIFICATION MECHANISMS}

by

Anya T. Edun

Florida International University, 2011

Miami, Florida

Professor Jesse S. Michel, Major Professor

This study explored the relationship between a new self-report measure built from justification mechanisms of aggression (i.e., the basis of conditional reasoning; James, 1998) with a traditional explicit measure and an implicit conditional reasoning measure of aggression. The construct validity and generalizability of the new measure were investigated by using non-work related criteria (violent acts, traffic violations, alcohol use, competitiveness, and agreeableness) in an undergraduate student sample. Correlations and moderated hierarchical multiple regressions were used to assess the relationships between variables. The results support the literature in that both explicit and implicit components of personality need to be examined. In conclusion, the newly developed measure fills a gap in the literature by operationalizing aggression as reasons for behaving aggressively. It is similar to the explicit aggression measure in that it is a self-report; however, the moderate correlation between the two suggests that each is measuring slightly different aspects of aggression. 


\section{TABLE OF CONTENTS}

$\begin{array}{ll}\text { CHAPTER PAGE } & \text { PAT }\end{array}$

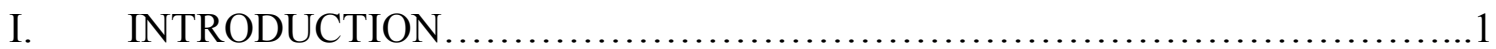

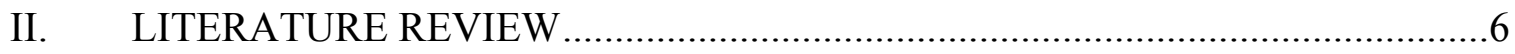

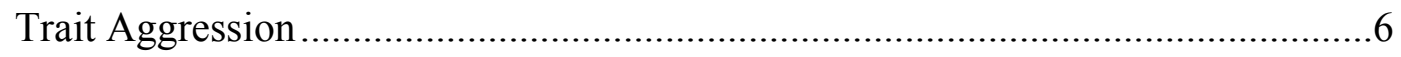

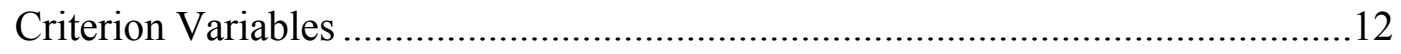

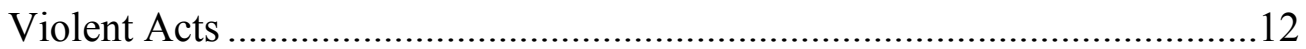

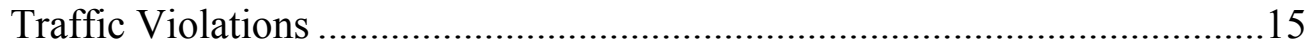

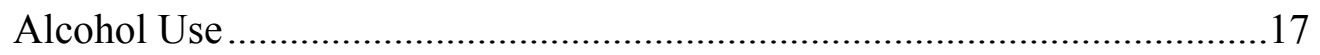

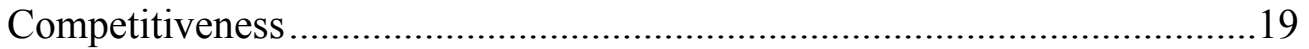

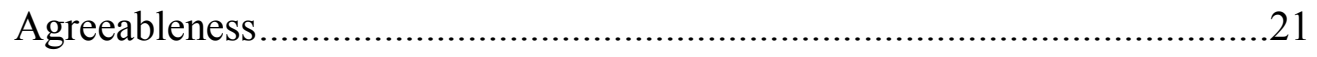

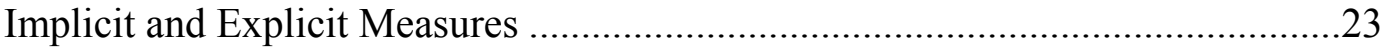

Self-Report Method ..........................................................................23

Conditional Reasoning Method ...............................................................25

Self-Report with Conditional Reasoning JMs..........................................22

Joint Self-Report and Conditional Reasoning Measurement .......................28

III. METHODOLOGY ................................................................................... 31

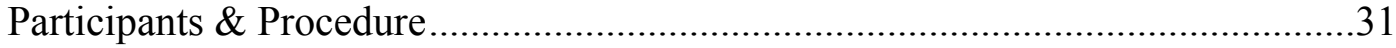

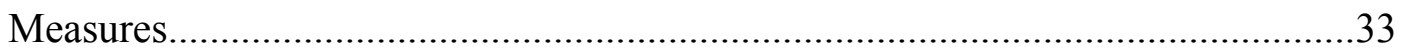

Buss-Perry Aggression Questionnaire (BPAQ) ..........................................33

Conditional Reasoning Test of Aggression (CRT-A)....................................33

New Aggression Self-Report Built on JMs ..............................................34

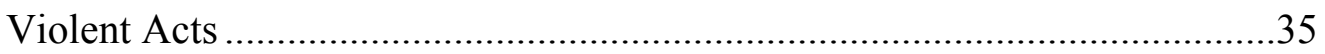

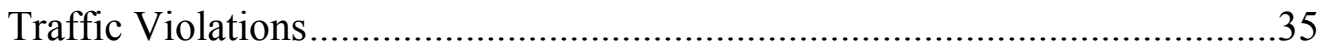

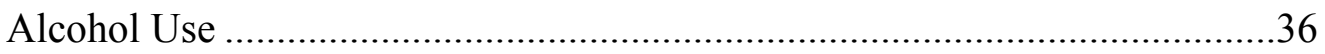

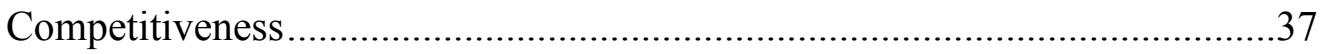

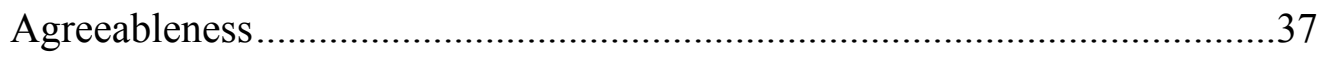

Socially Desirable Response Bias (SDRB) .............................................38

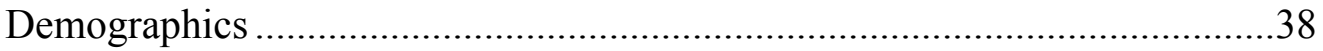

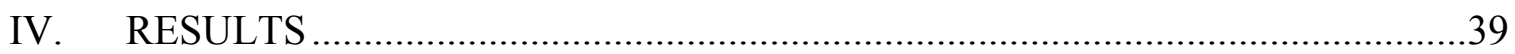

Effects of Predictor Measures on Violent Acts.....................................................44

Effects of Predictor Measures on Traffic Violations ............................................45

Effects of Predictor Measures on Alcohol Use...................................................46

Effects of Predictor Measures on Competitiveness ..............................................46

Effects of Predictor Measures on Agreeableness.................................................48 


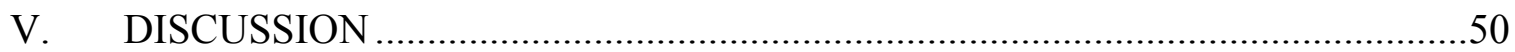

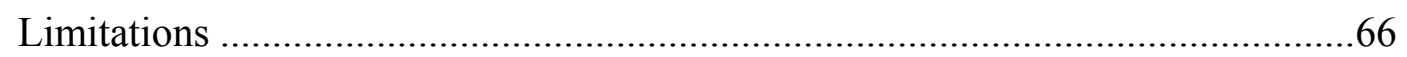

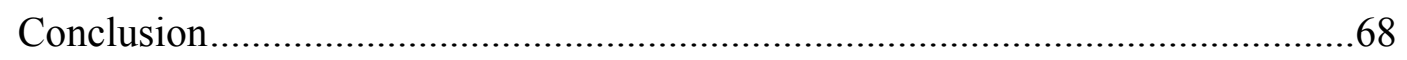

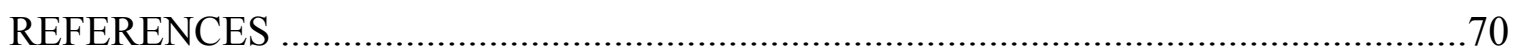




\section{LIST OF TABLES}

TABLE

PAGE

1. Summary of Sample Sizes, Means, Standard Deviations, and Correlations for All Study Variables

2. Moderated Regression Analyses Examining the Main and Interaction Effects of Each Aggression Measure on Violent Acts.

3. Moderated Regression Analyses Examining the Main and Interaction Effects of Each Aggression Measure on Traffic Violations

4. Moderated Regression Analyses Examining the Main and Interaction Effects of Each Aggression Measure on Alcohol Use.....

5. Moderated Regression Analyses Examining the Main and Interaction Effects of Each Aggression Measure on Competitiveness

6. Moderated Regression Analyses Examining the Main and Interaction Effects of Each Aggression Measure on Agreeableness

7. Frequency Distribution of Scores for the CRT-A 


\section{CHAPTER I}

\section{INTRODUCTION}

The way in which a person behaves is shaped by underlying, tacit motives to behave in that manner. Within the personality literature, aggression is referred to as an antisocial trait. Antisocial personality traits are characterized by socially undesirable and unacceptable behaviors. Aggression is not widely endorsed by social norms. Social norms promote prosocial behaviors and provide guidelines for how to conduct one's self in given situations. In other words, social norms dictate what is and is not expected in social interactions. The likelihood of people acknowledging and openly admitting that they are aggressive is fairly small. For the most part, people do not like diverging from the norm. Unlike prosocial traits, people are rarely eager to acknowledge having an aggressive personality because of the stigma associated with being labeled as such. If social norms signify what is expected, then failing to adhere to those expectations is viewed as deviance. For aggressive individuals, it may be difficult for them to realize and admit that they have implicit motives to behave aggressively. As a result, when trying to measure whether or not a person is aggressive, the problem arises that the participant alters his or her response to appear less aggressive and more prosocial (i.e., socially desirable response bias, SDRB; Baumeister, Smart, \& Boden, 1996).

Traditionally, within organizational psychology, self-reports have been a common method used in personality testing (Sacket \& Larson, 1999; Schwarz, 1999). Their purpose is to directly obtain data on how respondents evaluate themselves and their personality traits. However, as common and useful as self-reports are they are also quite problematic and limited in the data that they can provide. Recently, some researchers 
(e.g., James, McIntyre, Glisson, Bowler, \& Mitchell, 2004; James, McIntyre, Glisson, Green, Patton, LeBreton, Frost, \& Russell, 2005) have started to focus their efforts on designing a new method of capturing individual disposition, called the Conditional Reasoning Measurement System (James, 1998). The measures are referred to as Conditional Reasoning Tests or CRTs. This psychometric approach was created by Lawrence James (1998) to make inferences about a person's personality disposition, especially motive-based dispositions that are often rejected, denied, or unknown by the individual. In particular, this study is focused on aggressive personality and the implicit assumptions that rationalize behaving aggressively.

For purposes of this study, explicit self-report surveys and conditional reasoning tests are referred to as explicit and implicit measures, respectively. Explicit measures require respondents to answer items that straightforwardly represent what the researcher wants to measure. For example, if a researcher wants to measure aggression explicitly, they could ask a statement such as: "I often feel angered by my peers." This statement asks the respondent to indicate to what extent he or she agrees with what is being said. On the other hand, implicit measures typically present problems that, at surface level, resemble ability-based problems but, in actuality tap into subconscious biases or motives. With this method, the researcher is looking to measure a specific predisposition but does so in an indirect, covert way.

Essentially, with the Conditional Reasoning Measurement System, the variable under consideration is no longer the focus; instead, problems are built from justification mechanisms (JMs) that rationalize, or justify, behaving one way over another (e.g., behaving aggressively versus non-aggressively; cf. James, 1998). Also, the process of 
inductive reasoning is the premise on which implicit measures are designed. Inductive reasoning involves presenting a specific scenario (e.g., a word problem) and then asking the respondent to derive a logical conclusion (i.e., motive-based response) to that scenario. The responses collectively would provide an idea of what the individual deems most logical (i.e., what their tacit motives predispose them to conclude).

Theoretically speaking, being able to indirectly measure antisocial personality traits can provide valuable information that would otherwise not be obtained from an explicit, self-report measure alone. Rather than asking participants to rate their agreement or disagreement with antisocial personality statements, conditional reasoning tests capture a participant's tendency to rationalize antisocial traits as acceptable by using logic-based problems. In other words, conditional reasoning problems can better elicit honest responses to antisocial personality traits simply because they do not outright ask respondents to do so. Individuals are less aware of the nature of the test and believe that they are solving problems based on cognitive ability rather than personality. Thus, with conditional reasoning, participants are expected to be less influenced by SDRB (LeBreton, Barksdale, Robin, \& James, 2007) and to report more honest appraisals of their behavioral tendencies even if they are socially unfavorable. Despite such benefits, conditional reasoning tests do have some drawbacks as well. For instance, they are quite time consuming and costly to administer. With these considerations, Michel and colleagues (in progress) developed a self-report measure based on JMs to quickly and inexpensively measure aggressive personality.

Research shows the added benefit of using an explicit measure and an implicit measure in combination to fully capture personality constructs (Bing, Stewart, Davison, 
Green, McIntyre, \& James, 2007; Bing, LeBreton, Davison, Migetz, \& James, 2007; Bornstein, 2002; James, 1998; Winter, John, Stewart, Klohnen, \& Duncan, 1998). Selfreport measures of conscious (explicit) cognitions have a history of low and often nonsignificant correlations with various implicit, usually projective, measures (Greenwald \& Banaji, 1995; McClelland, Koestner, \& Weinberger, 1989; Nisbett \& Wilson, 1977). Accordingly, there are two processes operating that need to be measured in personality testing. As evidenced in the literature, researchers use separate implicit and explicit measures and evaluate their results together. But, in an attempt to be more efficient in test administration and evaluation, little attention has been given to integrating the two methods into one to see if a self-report built from JMs can capture implicit personality just as well as a single CRT. Also, how such a measure compares to a single self-report measure warrants consideration as well.

At present, there is one study that has constructed a self-report measure of aggression from JMs (James et al., 2004). With a sample of 337 undergraduates, a correlation of .17 $(p<.01)$ was obtained between scores on the Conditional ReasoningAggression (CR-A) scale and a self-report built from CR-A JMs. James and colleagues (2004) "designed a 21-problem self-report instrument on which respondents described the degree to which assumptions or conclusions engendered by the JMs [Hostile Attribution Bias, Potency Bias, Retribution Bias, Victimization by Powerful Others Bias, Derogation of Target Bias, and Social Discounting Bias] applied to them" (p. 289). A sample item for Victimization by Powerful Others Bias is: "I feel that I often get taken advantage of in life." Respondents would then indicate their level of agreement on a 5-point scale ranging from 1 , strongly disagree, to 5 , strongly agree. Despite the correlation being significant, 
the self-report accounted for less than $3 \%$ of the variance in the CR-A measure. Thus, the results suggest that individuals cannot accurately describe their implicit biases when presented with explicit statements to do so (James et al., 2004). However, besides not providing a detailed methodology for how the measure was created, there are a few additional shortcomings that will be addressed later in the paper.

All in all, one of the goals of this study is to explore how well the new aggression measure (Michel, Pace, Edun, Sawhney, \& Thomas, in progress), a self-report based on conditional reasoning JMs, can best predict theoretically-related criterion variables. Secondly, this study will address the construct validity and generalizability of the new scale by using non-work related criteria in an undergraduate student sample. The criterion variables of interest are: violent acts, traffic violations, alcohol use, competitiveness, and agreeableness. In addition, a measure of SDRB will be included to control for the antisocial nature of the study's main variable (i.e., aggression) and select criterion variables (i.e., violent acts, traffic violations, alcohol use, and competitiveness). In the following section, a brief review of all the variables and their relationships is provided, beginning with trait aggression. 


\section{CHAPTER II}

\section{LITERATURE REVIEW}

\section{Trait Aggression}

Before operationally defining aggression, a distinction must be made between trait aggression and state aggression. In this study, the main focus is on dispositional or trait aggression which is a relatively stable predisposition to respond to various situations aggressively. In comparison, state aggression is a momentary, conscious feeling of aggression, expressed in response to an immediate, provoking stimulus. Due to the nature of this study, when referring to aggression, I am referring to stable, trait aggression and not state aggression. Conditional reasoning measures a person's proclivity or underlying motives to reason in ways that justify behaving aggressively. In other words, individuals are implicitly ready to engage in some form of aggressive behavior now and in the future (James, 1998; James \& Mazerolle, 2002; James \& McIntyre, 2000). As a result, conditional reasoning measurement inherently takes into account a person's stable predisposition to behave aggressively in differing situations across time (i.e., the definition of trait aggression).

What exactly is aggression? To answer this question we would need to look at the definition of aggression. However, one of the main problems in the literature is that there are too many competing definitions and ways in which to operationalize aggression, also referred to as the criterion problem (Parrot \& Giancola, 2007; Barratt \& Slaughter, 1998; Coie \& Dodge, 1998; Geen, 2001). For instance, aggression has been defined as the intention to harm another living being (Baron \& Richardson, 1994) as well as the actual delivery of harm regardless of intent (Berkowitz, 1989; Dollard et al., 1939; Feshbach, 
1964; Bandura, 1973). Besides slight definitional nuances, personality researchers have also frequently used aggression interchangeably with anger and hostility (Eckhardt, Norlander, \& Deffenbacher, 2004; Spielberger, Jacobs, Russell, \& Crane, 1983).

Research has shown that these variables are strongly correlated with one another and likely tap into the same latent construct (e.g., Martin, Watson, \& Wan, 2000). In looking at measures, it is clear that hostility scales often reference aggression and anger (e.g., "Whoever insults me or my family is asking for a fight," "It makes my blood boil to have somebody make fun of me;” Buss \& Durkee, 1957), that anger scales often reference aggression and hostility (e.g., "When I get mad, I say nasty things;" Spielberger, 1988), and that aggression scales often reference anger and hostility (e.g., "When frustrated, I let my irritation show;" "I am sometimes eaten up with jealousy;” Buss \& Perry, 1992). Thus, despite the subtle differences between anger, hostility, and aggression, the similarities are certainly far more evident.

Anderson and Bushman (2002) defined aggression as "any behavior directed toward another individual that is carried out with the proximate (immediate) intent to cause harm" (p.28). Anderson and Bushman point out that behavior is only considered aggressive when it will harm the target and when the target is motivated to avoid the behavior (Bushman \& Anderson, 2001; Baron \& Richardson, 1994; Berkowitz, 1993; Geen, 2001). Thus, by definition, accidental harm is not considered aggressive because it is not intended to do so. The authors further argue for a distinction between proximate and ultimate goals. For example, to assault a person has harm-based goals and to steal has profit-based goals (Ramírez \& Andreu, 2006; Anderson \& Bushman, 2002). Therefore, 
for assault and theft, the ultimate goals differ but at the proximate level they are similar because they both include the intent to harm the victim.

Dodge and colleagues (Dodge \& Coie, 1987; Dodge, Lochman, Harnish, Bates, \& Pettit, 1997) defined aggression in terms of reactive and proactive aggression. Reactive aggression is described as a hostile response to a perceived threatening stimulus. The authors also stated that the perception of threat and feeling of anger "push" an individual to react aggressively. Therefore, reactive aggression is the process of getting even for a threatening or anger-producing act caused by another person. On the other hand, proactive aggression is caused without any immediate provocation; instead, it is used to gain resources or control over others. Proactive aggression, characterized by behaviors such as bullying, dominance, and coercion, aims to gain resources or to threaten and control others (Dodge et al., 1997). According to Dodge and Coie (1987), the anticipated outcome "pulls" aggressive behavior.

Arnold Buss (1961) defined aggression as "a response that delivers noxious stimuli to another organism” (p. 1). In operationalizing aggression, Buss (1961) identified three overlapping types of aggression: Physical-Verbal, Active-Passive, and DirectIndirect. The Physical-Verbal dimension differentiates using either physical force or words to harm others. The Active-Passive dimension distinguishes between actively aggressing against another individual versus not doing something that, in turn, inflicts harm on another. Lastly, the Direct-Indirect dimension refers to causing harm in a direct, face-to-face manner or in a subtle, roundabout manner (Ramírez \& Andreu, 2006). These dimensions overlap in the sense that a person can verbally attack someone indirectly, 
such as spreading malicious rumors throughout a company. Also, if a person is engaging in physical aggression then presumably their actions are both active and direct as well.

Neuman and Baron (1998), focusing primarily on an organizational context, defined aggression as "all forms of behavior by which individuals attempt to harm others" (p. 393). Using exploratory factor analysis, the authors identified three categories of aggression: Expressions of Hostility, Obstructionism, and Overt Aggression. Expressions of Hostility refers to behaviors that are verbal (e.g., swearing, yelling, and verbal assault) and nonverbal (e.g., facial expressions, body language, and obscene gestures). Obstructionism, also known as passive or covert aggression, includes acts such as withholding valuable information or resources from another individual that may impede their ability to complete a task. The clandestine nature of Obstructionism allows aggressive acts to go unnoticed unlike Neuman and Baron's third category of aggression, Overt Aggression. This final category of aggression is defined by outright physical displays of aggression such as punching, pushing, fighting, and shoving. Similar to Buss (1961), Neuman and Baron acknowledge differences in the way that aggression is expressed. However, there is an apparent lack of agreement in how to categorize such differences. For instance, Buss pairs verbal and physical aggression in one dimension, while, Neuman and Baron separate verbal from physical aggression and, instead, combine verbal and nonverbal aggression in one category called "Expressions of Hostility."

The most widely known and frequently used questionnaire on aggression was the Hostility Inventory developed in 1957 by Buss and Durkee (Lange, Pahlich, Sarucco, Smits, Dehghani, \& Hanewald, 1995; Buss \& Perry, 1992). The authors of the Hostility 
Inventory wanted to identify meaningful subclasses because a single, "global evaluation of hostility would seem to contain considerable ambiguity" (Buss \& Durkee, 1957, p. 343). This inventory, consisting of 75 true-false questions ( 66 for hostility and 9 for guilt), was divided a priori into the following eight subscales: Assault (physical violence against others), Indirect Hostility (roundabout and undirected aggression such as malicious gossip or practical jokes), Irritability (a readiness to explode with negative affect at the slightest provocation), Negativism (oppositional behavior usually directed against authority), Resentment (jealously and hatred of others), Suspicion (projection of hostility onto others), Verbal Hostility (negative affect expressed in both the style and content of speech), and Guilt (feelings of being bad, having done wrong, or suffering pangs of conscience; Buss \& Durkee, 1957). The subscales were factor analyzed and two factors emerged. Factor one, consisting of Assault, Indirect Hostility, Irritability, and Verbal Hostility is called Aggressiveness ("a 'motor' component that involves various aggressive behaviors," p. 348) and factor two, consisting of Resentment and Suspicion, is called Hostility (“an 'emotional' or 'attitudinal' component," p. 348).

Most recently, Buss and Perry (1992) categorized aggression into three parts instrumental, emotional, and cognitive - to capture a person's predisposition to engage in antisocial behavior. In creating an updated measure of aggression (i.e., the Buss-Perry Aggression Questionnaire, BPAQ), the authors used exploratory factor analysis to categorize 29 aggression items into four subtraits: Physical Aggression, Verbal Aggression, Anger, and Hostility. Physical and Verbal Aggression refers to instrumental behavior because it involves hurting or harming others, which represents the instrumental or motor component of behavior. Anger involves physiological arousal and preparation 
for aggression, which represents the emotional or affective component of behavior. Hostility involves feelings of ill-will and injustice, which represents the cognitive component of behavior (Buss \& Perry, 1992). Additionally, within the study, the authors suggest that anger links the instrumental aspects of aggression (i.e., Physical and Verbal Aggression) to the cognitive aspects (i.e., Hostility). In essence, anger is a prelude to behaving aggressively. While hostility, on the other hand, can interact in one of two ways; firstly, once the high-arousal state (i.e., anger) wears off, then presumably cognitive feelings of hostility set in or secondly, hostile feelings (e.g., suspicion of others' motives, resentment, etc.) may trigger a person's physiological response (i.e., anger) in preparation for immediate aggression. Thus, there have been many ways to conceptualize aggressive behavior which makes defining aggression quite ambiguous and problematic. In this study, the Buss and Perry (1992) definition and operationalization of aggression will be used.

Nevertheless, despite all of the ways in which to conceptualize aggression one thing has remained consistent. Historically, aggression measures have looked primarily at explicit, behavioral manifestations of aggression. In 1957, Buss and Durkee branched away from looking solely at behavioral manifestations by considering emotional, or attitudinal, components of aggression (i.e., resentment and suspicion). Then, in 1992, with the highly cited Buss-Perry Aggression Questionnaire, aggression was defined not only by a motor component (i.e., Physical and Verbal Aggression) but by an affective (i.e., Anger) and cognitive component (i.e., Hostility) as well. With the recent exception of conditional reasoning, to be discussed in more depth later in this paper, measures of aggression have been explicit, self-reports. But, the goal of this study is to tap into the 
subconscious state of aggression. Therefore, the newly developed self-report (Michel, Pace, Edun, Sawhney, \& Thomas, in progress) looks to fill a gap in the literature by examining implicit JMs, based on the conditional reasoning approach, instead of traditional behavioral expressions of aggression.

\section{Criterion Variables}

In the following section, I will identify key variables that have been shown to relate to aggressive personality. Particularly, the variables of interest are violent acts, traffic violations, alcohol use, competitiveness, and agreeableness.

Violent Acts. Nowadays, it seems as though violent acts are headlined in the news every single day. Certainly, the media is criticized for sensationalizing news reports, however, the fact still remains that regardless of how it is delivered, violent acts are very much a widespread occurrence. Whether it is the setting on fire of a young boy by his peers or a well-known athlete charged with sexual assault against a minor, violence clearly plagues our society. Now, the question asked is why do people engage in violent behaviors such as domestic violence, murder, assault, rape, robbery, and the like? Many studies have been done, especially within the criminology/criminal justice and sociology literature, to answer this very question.

For example, alcohol and drug use (e.g., Bennett \& Lawson, 1994; Fals-Stewart, 2003; Field, Caetano, \& Nelson, 2004; Roizen, 1993), exposure to physical violence as a child (e.g., Bergen, Martin, Richardson, Allison, \& Roeger, 2004; Crooks, Scott, Wolfe, Chiodo, \& Killip, 2007; Smith \& Thornberry, 1995; Swanston, Parkinson, O'Toole, Plunkett, Shrimpton, \& Oates, 2003), playing violent video games (e.g., Anderson \& Bushman, 2001; Anderson, Gentile, \& Buckley, 2007; Polman, Orobio de Castro, \& Van 
Aken, 2008), and animal cruelty (e.g., Hensley \& Tallichet, 2009; Mead, 1964; MerzPerez \& Heide, 2003; Merz-Perez, Heide, \& Silverman, 2001; Tallichet \& Hensley, 2004) have all been shown to relate to future violent behaviors. However, another important area of interest in understanding why people take part in violent acts is personality. For instance, some individuals may be more inclined to engage in violent acts simply because of their inherent disposition to do so. The following review describes aggressive personality and its relation to violent acts.

According to Jackman (2002), research on violence is characterized by two overarching themes. "First, violence is typically assumed to be motivated by hostility and the willful intent to cause harm. Second, it is usually assumed that violence is deviant legally, socially, or morally - from the mainstream of human activity" (p. 388). The definition alone sounds similar to that of aggression. Thus, major overlap can be expected between the aggression and violence constructs. In an introduction to a four-volume collection sponsored by the National Research Council entitled Understanding and Preventing Violence, Reiss and Roth (1993) defined violence as "behavior by persons against persons that intentionally threatens, attempts, or actually inflicts physical harm" (p.35). Additionally, they went on to say that "the behaviors included in this definition are largely included in definitions of aggression. A great deal of what we believe about violence is based on psychosocial research on aggressive behaviors..." (p. 35).

Reiss and Roth's (1993) definition restricts violence to behaviors that are interpersonal, inflict or threaten physical harm, and are motivated by harmful intent. However, despite considerable overlap between the two constructs, each differs in the scope of behaviors defined. According to Berkowitz (1993), aggression and violence can 
be viewed on a continuum with violence representing the most extreme and brute form of aggression. Thus, the sole intent of violence is to hurt another and cause serious physical injury (Berkowitz, 1993). On the basis of this reasoning, the definition of violence does not consider verbal abuse, psychological/emotional abuse, or other indirect forms of aggression (e.g., spreading rumors and lies, gossiping, and withholding information to impede others' attainment of goals) as violent acts. Therefore, by definition, all violent behaviors are aggressive whereas not all aggressive behaviors are violent. This differentiation is the basis on which researchers can measure aggression as a valid predictor of violent behavior.

An extensive body of research shows that early aggressive behavior is strongly associated with later criminal behavior and violence (e.g., Cairns \& Cairns, 1994; Coie \& Dodge, 1998; Loeber \& Hay, 1997; Rutter, Giller, \& Hagell, 1998). For example, family and marital violence research reveals that nonphysical aggression often precedes physical violence (Murphy \& O’Leary, 1989; Purdy \& Nickle, 1981; Sonkin, Martin \& Walker, 1985; Walker, 1979). Also, Nagin and Tremblay (1999) showed that physical aggression, measured by assessments on children between the ages of 6 and 15, is linked to physical violence as an older teenager at age 17 . Results reveal that as aggressive teenagers grow older they are the ones to commit the majority of all crimes in the United States (Snyder \& Sickmund, 1999). In looking at workplace outcomes, aggression leads to various counterproductive work behaviors such as interpersonal revenge (Bies \& Tripp, 1998), robbery (Toscano \& Weber, 1995), and in the rare but most extreme case, violence (Fox \& Spector, 1999). 
One of Buss and Perry's (1992) three components of aggression is anger. It is the physiological arousal and preparation for aggression. Empirical research supports the claim that frequently high levels of anger can be quite problematic. Individuals prone to anger are more aggressive in their behavior (Bettencourt, Talley, Benjamin, \& Valentine, 2006). Understandably, this is expected because anger, the affective or emotional component of aggression, is the prelude to the motor component of aggression (i.e., violent acts). Thus, if a person is more often than not angry then the likelihood of engaging in violence is considerably much higher as well. Some violent outcomes of anger that have been examined are murder (e.g., Berkowitz, 1993), child abuse (e.g., Nomellini\& Katz, 1983), and domestic violence (e.g., Barbour, Eckhardt, Davison, \& Kassinove, 1998). Burman, Margolin, \& John (1993) found that both violent husbands and their wives are characterized by high levels of observed anger and are likely to reciprocate their partner's anger with similar anger for a relatively long period of time. Thus, a substantial amount of research exists supporting the relationship between aggressive personality and violent acts.

Hypothesis 1: There is a positive relationship between aggression and violent acts.

Traffic Violations. How many times have we been in "close calls" while driving? It is highly likely that we have each experienced at least one incident of road rage where another driver dangerously tailgated us, or honked their horns incessantly at us, or failed to use their indicator and cut us off, or almost collided with us because they wanted to avoid a red light. These examples are just a few to illustrate aggressive driving behaviors while behind the wheel. In the United Sates, the National Highway Traffic Safety Administration (NHTSA, 2010) reported that in 2009, there were 33,963 people killed 
from motor vehicle crashes. Despite being the lowest fatality rate since 1954 and approximately an $8.9 \%$ decline from 2008 with 37,261 fatalities, motor vehicle crashes still ranks among one of the leading causes of death in the United States (NHTSA, 2010).

Traffic accidents have a variety of causes but one such contributor is aggressive and unsafe driving. Some researchers focus on the environmental or situational triggers of road rage such as driver anonymity, roadway congestion, degree of traffic obstruction, weather conditions, time constraints, and the presence of passengers in the driver's vehicle (e.g., Edwards, 1999; Ellison-Potter, Govern, Petri, \& Figler, 1995; Novaco, Kliewer, \& Broquet, 1991; Novaco, Stokols, Campbell, \& Stokols, 1979; Novaco, Stokols, \& Milanesi, 1990; Shinar \& Compton, 2004). However, in addition to the aforementioned scenarios, individual differences in reacting with anger have also been shown to trigger driver road rage as well (Arnett, Offer, \& Fine, 1997; Deffenbacher et. al, 2000; Deffenbacher, Lynch, Oetting, \& Yingling, 2001; Deffenbacher, Oetting, \& Lynch, 1994). Individuals who reported high levels of anger reported more dangerous driving behaviors, lifetime accidents, minor accidents, close calls, and moving violations (Deffenbacher et al., 2000; Lynch, Deffenbacher, Filetti, \& Dahlen, 1999).

Recurrent in the aggressive driving literature is the discussion of trait versus state anger. In one study, anger was found to be the only mood state associated with high speed driving in adolescents (Arnett et al., 1997). Similar to trait and state aggression discussed earlier, trait anger is a stable predisposition to experience anger. In other words, individuals with high trait anger interpret a wide array of situations as anger-provoking and react to those situations with an elevated level of anger (Spielberger, 1988). Therefore, those high on trait anger are more likely to experience frequent and intense 
anger because of their natural tendency to do so. They are also more likely to display aggressive behaviors resulting in traffic violations and automobile accidents, compared to those low on trait anger (Deffenbacher et al., 2000; Deffenbacher et al., 2001). Another construct found to be related to aggressive driving is hostility. As the cognitive component of aggression (Buss \& Perry, 1992), those who harbor feelings of ill-will or hostility are more inclined to drive aggressively as well (Galovski \& Blanchard, 2002; Harris \& Houston, 2010; Norris, Matthews, \& Riad, 2000). They are more easily angered while driving (DePasquale, Geller, Clarke, \& Littleton, 2001) which increases the probability of aggressive behavior.

Hypothesis 2: There is a positive relationship between aggression and traffic violations. Alcohol Use. There exists a large body of literature examining the relation between alcohol consumption and aggressive behavior. Both correlational and experimental research designs have been used to demonstrate this relationship, however, experimental designs far outnumber correlational ones. Thus, the accumulation of experimental studies provides substantial support for the causal relationship between alcohol and aggression. A number of meta-analytic studies (Bushman \& Cooper, 1990; Hull \& Bond, 1986; Ito, Miller, \& Pollock, 1996; Steele \& Southwick, 1985) and narrative reviews of experimental research (Gustafson, 1992; Kelly \& Cherek, 1993; Pihl, Peterson, \& Lau, 1993; Taylor \& Chermack, 1993) conclude that alcohol consumption does indeed cause aggressive behavior.

Taylor and colleagues have found that individuals who receive alcohol are more aggressive than those who receive a placebo or a nonalcoholic beverage (Bailey \& Taylor, 1991; Chermack \& Taylor, 1995; Gantner \& Taylor, 1992; Laplace, Chermack, 
\& Taylor, 1994; Shuntich \& Taylor, 1972; Taylor \& Gammon, 1975, 1976; Taylor, Gammon, \& Capasso, 1976; Taylor, Schmutte, Leonard, \& Cranston, 1979; Taylor \& Sears, 1988). Others have also found that subjects receiving alcohol behave in a more aggressive manner as evidenced by administering higher levels of shock and for longer time durations compared to those receiving nonalcoholic or placebo beverages (Giancola \& Zeichner, 1997, 1995; Gustafson, 1985; Pihl \& Zacchia, 1986; Zeichner, Allen, Giancola, \& Lating, 1994; Zeichner, Giancola, \& Allen, 1995; Zeichner \& Pihl, 1979, 1980; Zeichner, Pihl, Niaura, \& Zacchia, 1982).

Extensive research has also been done to illustrate how alcohol consumption affects an individual's cognitive and psychomotor functions. The pharmacological properties of alcohol have been found to decrease a person's inhibition by diminishing fear responses (Ito, Miller, \& Pollock, 1996; Pihl, Peterson, \& Lau, 1993), increase psychological and physiological arousal (Giancola \& Zeichner, 1997; Graham, Wells, \& West, 1997), and disrupt higher-order cognitive functioning (Giancola, 2004; Steele \& Josephs, 1990). Despite these pharmacological effects, alcohol does not increase aggression in all situations or in all persons. For instance, situational factors such as social pressure (Taylor \& Sears, 1988), provocation (Giancola et al., 2002), expectancy belief that alcohol causes aggression (Brown, Goldman, Inn, \& Anderson, 1980; Crawford, 1984a, 1984b), and drinking setting (Tremblay, Graham, \& Wells, 2008) have all been shown to moderate the alcohol-aggression link. Moreover, theorists have similarly emphasized the moderating role of individual differences, particularly personality traits, in the alcohol-aggression relation (Chermack \& Giancola, 1997). 
Conceptually, it is thought that alcohol facilitates aggression to a greater extent among individuals who are predisposed to behave aggressively (Collins, Schlenger, \& Jordan, 1988; Pernanen, 1991). Consistent with this view, studies indicate that higher levels of trait aggression (Bailey \& Taylor, 1991; Giancola, 2002a), irritability (Giancola, 2002b), and trait anger (Parrott \& Zeichner, 2002) as well as lower levels of dispositional empathy (Giancola, 2003) and anger control (Parrott \& Giancola, 2004) increase the likelihood of intoxicated aggression.

One of the numerous personality traits found to moderate the alcohol-aggression relation is trait aggression, which reflects one's dispositional tendency to engage in aggressive behavior (Buss \& Perry, 1992). In comparison with others, this variable has arguably received the most empirical attention as a potential risk factor for alcoholrelated violent behavior. Specifically, laboratory studies have consistently shown that acute alcohol intoxication increases aggressive behavior to a greater extent among individuals who report higher, in relation to lower, levels of trait aggression (Bailey \& Taylor, 1991; Eckhardt \& Crane, 2008; Giancola, 2002a; Giancola, Godlaski, \& Parrott, 2006; Giancola \& Zeichner, 1995; Moeller, Dougherty, Lane, Steinberg, \& Cherek, 1998). Also, alcohol consumption has been found to increase aggression more for individuals who have aggressive dispositions (Bailey and Taylor, 1991; Giancola, 2002a) and who are prone to anger (Giancola, 2002b; Parrott \& Giancola, 2004; Parrott \& Zeichner, 2002).

Hypothesis 3: There is a positive relationship between aggression and alcohol use.

Competitiveness. Historically, from an evolutionary theory perspective, aggression and competitiveness have continually been shown to correlate (Archer, 1992, 
2004; Campbell, 1995, 1999; Daly \& Wilson, 1994). Competitiveness has been defined as "the enjoyment of interpersonal competition and the desire to win and be better than others" (Spence \& Helmreich, 1983, p. 41) and, "two or more individuals challenging for a limited resource, which results in one winning and the other losing the resource (Archer \& Webb, 2006, p. 465).” On the basis of these definitions, competitiveness is basically the rivalry between individuals resulting in one side succeeding and the other side losing. Therefore, it seems that more aggressive individuals would find enjoyment in competition because they would be able to establish dominance over others. Human competition is innate; commonly referred to as the "survival of the fittest," humans are instinctively wired to compete against one another especially for valued goods and resources. Even though the focus of competition may have changed from hundreds of years ago, people still regularly engage in it.

Rationally, the existence of aggressiveness and competitiveness seem to go handin-hand. For instance, when someone thinks of competition, images of a sporting event may come to mind. In such an environment, it is common to hear coaches, teammates, parents, and/or spectators yelling, "be aggressive," "show them who's boss," "demolish them," at the players. Such terms illustrate the charged emotions (i.e., aggressiveness) and drive to win when in competition. On the other hand, except for the occasional sarcastic remarks, it is rare to hear someone say "take it easy on them," and "don't give it your all." Thus, competition inevitably involves some form of aggressiveness to win and be better than others. In the present study, it is presumed that those who are more aggressive will likely be more competitive than those who are not. Furthermore, the likelihood of a competitive person engaging in aggressive behaviors is high considering 
that aggression can be physical or verbal which, as illustrated by the example above, is acceptable in certain competitive situations. Also, the other two components of aggression, anger and hostility, can occur as well in competitive situations when a person feels ill-will toward others (e.g., an opponent, a coworker, a classmate, etc.) or is physically stirred by a situation because they view their goods or resources are at stake.

Buss and Perry (1992) included the competitiveness construct in their original scale development study with the notion that competitiveness "might lead to social conflict and therefore would be linked to aggression" (p. 453). Their results revealed that competitiveness did in fact correlate with all four subscales of the Aggression Questionnaire and that a positive relationship exists between the two constructs. Further support of the relationship between aggression and competition can be found in Type A/B personality research (Friedman \& Rosenman, 1974). Indeed, Type A/B personality research has received much criticism because of the many conceptualizations of each personality type. But, there are some global characteristics of Type A personality that are largely agreed upon, such as, competitiveness, aggression, time urgency, impatience, goal-orientation, and achievement-striving (Rosenman, 1978). Type A personality studies repeatedly show the positive relationship between aggression and competitiveness, thus, helping to strengthen the expected relationship between the two constructs in the present study.

Hypothesis 4: There is a positive relationship between aggression and competitiveness. Agreeableness. "The agreeable person is fundamentally altruistic. He or she is sympathetic to others and eager to help them, and believes that others will be equally helpful in return" (Costa \& McCrae, 1992, p. 15). On the basis of this definition, 
agreeableness is very much contrary to aggression. A convincing number of studies show the negative relationship between the two constructs (e.g., Caprara, Barbaranelli, \& Zimbardo, 1996; Martin, Watson, \& Wan, 2000; Ruiz, Smith, \& Rhodewalt, 2001). Agreeableness is a highly recognized construct in personality research because of its use in Costa and McCrae's Five Factor Model (FFM; 1992). The FFM, also known as the "big five," presents five broad domains, or factors, to describe human personality; the five factors are Openness to Experience, Conscientiousness, Extraversion, Agreeableness, and Neuroticism. According to Sharpe and Desai (2001), compared with the other big five dimensions, agreeableness and neuroticism were the most predictive of trait aggressiveness, as measured by the Buss-Perry Aggression Questionnaire. Specifically, the results showed a strong negative correlation between agreeableness and all four subscales of the Aggression Questionnaire (i.e., Physical Aggression, Verbal Aggression, Anger, and Hostility).

Intuitively speaking, such a relationship makes sense given that individuals high in aggression would possess characteristics similar to those low in agreeableness (e.g., little concern for others, ill-feelings toward and distrust of others, assumed hostility of others, cold-heartedness, etc.). Likewise, individuals low in aggression would possess characteristics similar to those high in agreeableness (e.g., friendliness, altruism, gentleness, warm-heartedness, etc.). As stated by Graziano \& Eisenberg (1997) and Watson \& Clark (1992b), agreeableness is a personality construct defined both in terms of prosocial attitudes, feelings, and behaviors as well as low anger and aggression.

Furthermore, much of the literature on agreeableness and aggression centers around the ability of those who are high on agreeableness to self-regulate antisocial 
behaviors and/or thoughts (e.g., Meier, Robinson, \& Wilkowski, 2006; Gleason, JensenCampbell, \& Richardson, 2004; Smits \& De Boeck, 2007). For instance, Meier and Robinson (2004) found that hostile thoughts predicted higher levels of anger and aggression only at low levels of agreeableness. Thus, agreeableness can be said to have attenuating effects on aggressive behavior, whereby the prosocial characteristics of agreeableness lessen the antisocial characteristics of aggression. Meier, Wilkowski, \& Robinson (2008), found in their experimental research that a 20-minute training session on agreeableness helped produce a $10 \%$ reduction in physical aggression. All in all, the repeated theme is that prosocial thoughts and feelings are incompatible with antisocial thoughts and feelings which, in turn, decrease aggression.

Hypothesis 5: There is a negative relationship between aggression and agreeableness. Implicit and Explicit Measures

In the following section we will look at the need for integrating explicit and implicit measurements in personality research. More specifically, we will briefly review the self-report and conditional reasoning methods. Then, we will discuss the newly developed aggression measure, a self-report built upon JMs. Lastly, we will address the differential prediction of the Conditional Reasoning Test-Aggression (CRT-A), the BussPerry Aggression Questionnaire (BPAQ), and the new aggression measure with the criterion variables of interest.

Self-Report Method. Because of its many advantages, self-report is a very common methodology used in data collection. The objective here is not to focus on the fine details of self-report but, instead, provide a basic understanding of the strengths and weaknesses of its use. In personality psychology, self-reports look to capture a person's 
attitudes, beliefs, opinions, judgments, and the like in a direct, straight-forward manner. Self-reports are both time and cost effective because they can assess many variables in a convenient, easy to use format. Also, they can reach many people in one administration and typically require minimal time to complete. Lastly, self-reports can directly capture thoughts and behaviors of the respondent, which is fundamental to the study of personality research.

Nonetheless, despite the aforementioned strengths, self-reports have a major drawback. As was mentioned previously, research participants want to present themselves in a way that makes them look as good as possible. Thus, this poses a problem because participants tend to underreport behaviors deemed antisocial and overreport behaviors considered prosocial. Especially if it is believed that others cannot determine whether or not they are faking, respondents likely present their "best" selves with more prosocial responses. A desire to present one's self in the best light is referred to as socially desirable response bias. According to Paulhus (2002), SDRB is the tendency to give positive self-descriptions. Also, Edwards (1957) defined social desirability as "the tendency of subjects to attribute to themselves in self-description, personality statements with socially desirable scale values and to reject those with socially undesirable scale values" (p. 6). Therefore, despite the advantage of self-report directly capturing a person's feelings and behaviors, it is this same quality that can be disadvantageous as well. Individuals have the ability to alter their responses to appear more favorable, which would be a huge impediment particularly to the study of aggressive personality. 
Conditional Reasoning Method. Recently, within the literature, there has been substantial research dedicated to conditional reasoning because of its inductive approach to measuring personality constructs. The first application of conditional reasoning within personality research involved assessing the dispositional component of achievementmotivation (Atkinson, 1957, 1964, 1978; McClelland, 1985). The basic premise for conditional reasoning stems from a concept called relative motive strength (RMS; James, 1998). The procedure for RMS is to assess what a person considers to be more logically reasonable when weighing motives to behave in different ways. For instance, in regards to achievement-motivation, whether a person consistently chooses to persevere on demanding tasks (motive to achieve) or avoid them (motive to avoid failure) illustrates their relative motive strength. It is not a single occurrence of favoring one motive over another that determines a person's dispositional tendency; instead, it is the recurring behavior.

Aggressive individuals often think of their actions as reasonable (Baron \& Richardson, 1994; Baumeister, Smart, \& Boden, 1996; Crick \& Dodge, 1994; Felson \& Tedeschi, 1993; Huesmann, 1988; James, 1998; Toch, 1993).Where aggressive individuals view their behaviors as acceptable, nonaggressive individuals consider those behaviors illogical and do not see the rationale behind engaging in them. With conditional reasoning, respondents are able to express their natural tendencies because of JMs. Justification mechanisms are tacit reasons as to why one way to behave is more logical than another. People who are particularly likely to engage in aggressive behavior have more elaborate and readily accessible aggression related cognitions (Anderson \& Bushman, 2002; Berkowitz, 1983, 1993; Huesmann, 1988). Therefore, aggressive JMs 
help make it possible for people to aggress without having to view themselves as sinful, malicious, or immoral. They assist aggressive individuals in fostering reasoning that their behavior is socially acceptable. Specifically, aggressive people feel that behaving aggressively ensures that they are not victims of others or society. Also, they feel that establishing power and retaliation are ways in which to defend and safe-guard themselves. From this perspective, it is evident why JMs, and subsequent acts of aggression, are often viewed as acceptable, assertive, and self-protective. Conversely, nonaggressive individuals hold JMs allowing them to feel that acting prosocially is more reasonable, as a result, they have a hard time seeing the rationale behind why aggressive individuals act the way they do.

The conditional reasoning approach makes the assumption that there are contrasting ways in which one can behave. As long as a behavior can be justified or rationalized by at least some people, conditional reasoning tests can be used. For example, people have varying proclivities to engage in one behavior versus another: achievement-striving versus fear of failure, honesty versus dishonesty, optimism versus pessimism, modesty versus egotism, and the list can go on and on. To capture the way in which a person behaves, conditional reasoning tests present scenarios and ask participants to select one of four general conclusions to logically follow each scenario. Two choices are completely invalid but are included to protect the indirect nature of conditional reasoning and the remaining two represent each of the opposing JMs (e.g., to aggress or not aggress). The answer choice selected from the two alternatives reflects the natural tendency of that participant to either engage in prosocial behavior (i.e., not aggress) or antisocial behavior (i.e., aggress). Therefore, with conditional reasoning, researchers are 
able to gather deeper information about personality because of logic-based scenarios that tap into personality from a subconscious, motive-driven perspective. Although relatively new, conditional reasoning promises to be a very valuable method to the advancement of personality and especially antisocial personality research.

Self-Report with Conditional Reasoning JMs. The newly developed aggression scale is built on aggressive JMs defined by James and colleagues (2005). The six JMs for aggression are: Hostile Attribution Bias, Potency Bias, Retribution Bias, Victimization by Powerful Others Bias, Derogation of Target Bias, and Social Discounting Bias. Hostile Attribution Bias is the assumption that people are motivated by the desire to harm others. Potency Bias is the assumption that social interactions are a struggle to establish dominance versus submissiveness. Retribution Bias is the assumption that exacting revenge is more important than preserving or maintaining a relationship. Victimization by Powerful Others Bias is the assumption that the powerful inflict harm on the less powerful, thus, viewing oneself as a victim of inequality, injustice, and oppression by more powerful others. Derogation of Target Bias is the tendency to consider those who are targets of aggression as dishonest, sinful, or immoral (cf. Wright \& Mischel, 1987). Lastly, Social Discounting Bias is the assumption that social norms restrict individuality and inhibits the fulfillment of needs. All in all, these aforementioned JMs are what allow aggressive individuals to rationalize their behaviors as acceptable because they frame aggressive behavior in ways that are rational and justifiable.

The new scale is not your typical self-report measure because it taps into an individual's reasoning (i.e., justification mechanisms) for whether or not to act aggressively. Because of the directness of items, most self-reports alert respondents to the 
trait(s) being measured. However, the new scale which is built on aggressive JMs presents items that indirectly measure aggressive tendencies. Therefore, unlike other selfreport measures, participants are able to respond in a direct fashion but with minimal awareness of the trait in question. One of the major flaws of self-report is response bias. However, conditional reasoning is designed to break through response bias by assessing the respondent's motive structures (cf. James, 1998). Accordingly, by combining selfreport with conditional reasoning JMs, the new scale hopes to measure aggression while also attenuating socially desirable response bias. Furthermore, the CRT-A is a proprietary measure that can only be administered in paper-and-pencil format, and requires approximately twenty-five minutes to complete. For those wanting to use this measure it can be a bit inconvenient. As a solution, the new aggression self-report (Michel, Pace, Edun, Sawhney, \& Thomas, in progress) looks to be more time and cost effective, easy to administer, and available to the public.

Joint Self-Report and Conditional Reasoning Measurement. Personality is a function of what is conscious and explicit as well as what is subconscious and implicit (Greenwald \& Banaji, 1995; McClelland, Koestner, \& Weinberger, 1989; Nisbett \& Wilson, 1977). New theories regarding the interaction between explicit and implicit measurements have been investigated by Bornstein (2002; process dissociation models) and Winter, John, Stewart, Klohnen, and Duncan (1998; channeling models). Evidently, there is great advantage to using both measurement methods when assessing personality. Typically, a single explicit measure and a single implicit measure are used to capture an individual's personality. However, the new aggression scale differs because it actually combines the two methods into one self-report with items built from aggression JMs. As 
was mentioned in the introduction, there is one study that created a self-report measure of aggression from JMs (James et al., 2004). Basically, reviewers of James et al.'s (2004) study asked the question: "What would be the relation between scores on the CR-A and scores obtained by simply asking respondents to describe their use of JMs on self-report items?" (p. 289). To answer this question, the authors put together a 21-item self-report from the aggressive JMs. The results indicated that combining the two methods into one only barely explained implicit motives to aggress. But, due to the fact that 1) it was not the authors' primary research question, 2) the scale development process was not described, and 3) the psychometric properties were not provided, results of the study should be interpreted with caution.

Exploratory Analysis 1: Because each of the 3 aggression measures tap into different aspects of aggression, they will differentially relate when compared to one another.

Bing and colleagues (2007) present a general model of personality prototypes to describe an individual's personality based on the interaction between implicit and explicit cognitions. "By crossing high and low conditions of implicit and explicit social cognitions, we generate a personality typology from which general cognitive processes and subsequent patterns of behaviors can be inferred and predicted" (Bing et al., p. 354). The five prototypes include: congruent presence (high implicit cognitions and high explicit cognitions), incongruent denial (high implicit cognitions and low explicit cognitions), incongruent overclaiming (low implicit cognitions and high explicit cognitions), congruent absence (low implicit cognitions and low explicit cognitions), and congruent average Joe/Jane (average implicit and explicit cognitions). The authors acknowledge that a continuum typically exists for both explicit and implicit cognitions, 
however, in the interest of simplicity they define only five overarching prototypes. In order to capture this personality typology, interaction terms will be included in the data analyses as recommended by Bing and colleagues (2007). Therefore, along with evaluating how the new aggression measure relates to a traditional self-report measure and a CRT measure, analyses will explore how each of the aggression measures relates to the criteria singularly and in combination.

Exploratory Analysis 2: Because each of the 3 aggression measures tap into different aspects of aggression, each will differentially relate to the criterion variables. Exploratory Analysis 3: Because each of the 3 aggression measures tap into different aspects of aggression, they will differentially relate to the criteria when used in combination. 


\section{CHAPTER III}

\section{METHODOLOGY}

\section{Participants \& Procedure}

The sample for this study was composed of undergraduate students enrolled at Florida International University (FIU). All participants received course credit for their participation. This was a 2-part study and students had the opportunity to earn up to two course credits, one credit for each part. Only students who completed Time 1 of the study (in-class) were eligible to participate in Time 2 (on-line); however, a student may have chosen to complete Time 1 and skip Time 2 without any penalty.

The study is divided into two parts because the CRT measure of aggression must be administered in person. For this reason, Time 1 consisted of all the predictor measures of aggression and Time 2 consisted of all the criteria measures. Furthermore, I wanted to have a time lapse between the predictors and criteria to lessen the effects of common method bias. Time 1 of the study was conducted in-class. Each participant received a packet consisting of a consent form, a unique participant identification number, and the following three measures: CRT-A, BPAQ, and new aggression scale (Michel, Pace, Edun, Sawhney, \& Thomas, in progress). Prior to starting, students were instructed to complete the packet materials in the order that they were placed. The reason for this order was to ensure that the CRT-A was first and participants were not primed by the items of the BPAQ or new scale. Additionally, to safeguard the integrity of the overall study, students were told that the study was assessing general personality and that they were helping to validate a new personality measure. Lastly, students were instructed to tear-off 
their participant identification numbers from the consent form and input that number in Time 2.

Time 2 was completed by participants one week after Time 1 through the FIU Sona-Systems website. After signing-up for Time 2 on Sona-Systems, participants would follow a link to the survey's website. Once they provided informed consent, each participant was instructed to input their unique participant identification number. These numbers linked data from Time 1 to data from Time 2 for each student. Students then completed the remainder of the survey which measured the following constructs: violent acts, traffic violations, alcohol use, competitiveness, agreeableness, and demographics.

A total of 433 students completed the in-class portion at Time 1 and 326 students completed the on-line portion at Time 2. For Time 2, after removing multiple responses and omitting surveys that did not provide a unique participant identification number, the sample size decreased to 293. Then, after merging Time 1 data with Time 2 and filtering out those who had five or more illogical answers on the CRT-A (i.e., the validity check built-in to the measure), the sample size dropped to 274 . Thus, the overall number of students who completed both parts of the study and who were less likely responding randomly is 274 . However, of those 274 students, some failed to complete the backside of measures and randomly skipped different items in either part, as a result, missing data was handled using pair-wise omission in the data analysis phase.

Ranging from 17 to 54 years of age, the average participant was approximately 21 years old. Approximately $69 \%$ of participants were female and 31\% male. Hispanics comprised the large portion of the sample (71\%), while $15 \%$ were Caucasian, $8 \%$ were African American, 4\% were Asian/Pacific Islander, and 2\% described themselves as 
“Other". The majority of students had a cumulative GPA of a 3.0 to $4.0(68 \%), 31 \%$ had a 2.0 to 2.9 , and $1 \%$ had less than a 1.9 . Lastly, $33 \%$ of participants were first-semester Freshman while $67 \%$ were not.

\section{Measures}

Buss-Perry Aggression Questionnaire (BPAQ).This is a 29-item scale used to measure aggression in participants. It includes four subscales: Physical Aggression $(\alpha=$ $.85)$ which consists of 9 items, Verbal Aggression $(\alpha=.72)$ which consists of 5 items, Anger $(\alpha=.83)$ which consists of 7 items, and Hostility $(\alpha=.77)$ which consists of 8 items. The measure has an overall internal consistency reliability of .89 (Buss \& Perry, 1992, p. 455). Test-retest reliability for each subscale is $.80, .76, .72$, and .72 , respectively, and an overall score of .80 (Buss \& Perry, 1992, p. 455). Each item is scored on a 5-point Likert scale ranging from "Extremely uncharacteristic of me" to "Extremely characteristic of me." Sample items from this measure include, "Given enough provocation, I may hit another person," "My friends say that I am somewhat argumentative," "I have trouble controlling my temper" and "Other people always seem to get the breaks." The overall alpha coefficient observed for this study's sample was .89. Conditional Reasoning Test of Aggression (CRT-A). The CRT-A is composed of 22 conditional reasoning problems that are derived from one or more of the following six JMs: Hostile Attribution Bias, Potency Bias, Retribution Bias, Victimization by Powerful Others Bias, Derogation of Target Bias, and Social Discounting Bias. The internal consistency estimates for each factor (with the exception of Derogation of Target Bias) are $.87, .82, .81, .76$, and .74 , respectively (James et al., 2004, p. 280) and the overall CRT-A alpha coefficient is .76 (James \& McIntyre, 2000, p. 46). The Derogation of 
Target Bias is not represented because only one of the CRT-A problems was designed to appeal to individuals who use this JM. In order to score the CRT-A, respondents are given a "+1" for every aggressive alternative they select, a " 0 " for every logically incorrect alternative they select, and a "-1" for every nonaggressive alternative they select. The scores are then summed and a high score, which can be a max of 22 ("+1" for each of the 22 conditional reasoning problems), indicates that respondents are implicitly prepared to justify behaving aggressively. A low score indicates that respondents hold more prosocial tendencies and are less likely to behave aggressively.

New Aggression Self-Report Built on JMs. With five items for each, this 30-item measure captures the six JMs of aggression (Hostile Attribution Bias, Potency Bias, Retribution Bias, Victimization by Powerful Others Bias, Derogation of Target Bias, and Social Discounting Bias; James et al., 2004; see Appendix A). Hostile Attribution Bias includes items such as "People make friends in order to use them to get ahead in life." A sample item for Potency Bias is "Life presents challenges that separate the weak from the strong." A sample Retribution Bias item is "People have the right to get revenge." A sample item for Victimization by Powerful Others Bias is "Those in power stay in power by keeping others down." An example item for Derogation of Target Bias is "Some people are just bad people." Lastly, Social Discounting Bias includes items such as "Any social rule that gets in the way of personal expression is a bad rule." The overall internal consistency reliability for the measure is .89 and the six subscale reliabilities range from 68 (Social Discounting Bias) to .88 (Retribution Bias; Michel et al., in progress). The overall alpha coefficient observed for this study's sample was .89 . 
Violent Acts. A modified version of the Conflict Tactics Scale (Straus, 1979) was used to measure violent acts. It is the most widely used instrument for research on intrafamily violence. It is a self-report capturing strategies (tactics) used in conflict during a 12 month period. The measure was adjusted to be less specific to intrafamily violence by omitting phrases such as "at my wife" or "at my husband." The three theoretically based tactics measured are: Reasoning, Verbal Aggression, and Violence. The Reasoning scale refers to "the use of rational discussion, argument, and reasoning an intellectual approach to the dispute" (p. 77). The Verbal Aggression scale refers to "the use of verbal and nonverbal acts which symbolically hurt the other, or the use of threats to hurt the other" (p. 77). The Violence scale refers to "the use of physical force against another person as a means of resolving the conflict” (p. 77). However, for purposes of this study, we are only interested in the Violence scale of the CTS measure.

Originally response categories asked for how many times each action had occurred during the past year, ranging from $0=$ Never to $5=$ More than Once a Month. I modified response options from frequency count to a more global 6-point rating scale (1 $=$ Never, $2=$ Almost Never, $3=$ Sometimes, $4=$ Fairly Often, $5=$ Very Often, $6=$ Always). Sample items/actions include "Threw, hit, or kicked someone," "Slapped someone," and "Physically restrained someone." In terms of internal consistency reliability, Straus (1979) reported that the Violence scale had the highest coefficient alphas of all three scales (p. 83). The overall alpha coefficient observed for this study's sample was .91.

Traffic Violations. The Aggressive Driving Behavior Scale (Houston, Harris, \& Norman, 2003) will be used to measure traffic violations. This 11 -item measure is 
divided into two factors: Conflict Behavior (7 items) and Speeding Behavior (4 items). Conflict Behavior measures driving behaviors that are directed towards others (e.g., horn honking, rude gestures, accelerating to prevent passing) and Speeding Behavior measures behaviors that may not be directed towards a specific target but are still potentially injurious to the driver, other motorists, and pedestrians (e.g., driving fast, close passing, tailgating). A sample Conflict Behavior item is "Honk when another driver does something inappropriate" and a sample Speeding Behavior item is "Follow a slower car at less than a car length." Participants rate the frequency with which they have engaged in each of the 11 behaviors over the past 6 months using a 6-point response scale $(1=$ Never, $2=$ Almost Never, $3=$ Sometimes, $4=$ Fairly Often, $5=$ Very Often, $6=$ Always) . The coefficient alphas are .73 and .68 for the Conflict Behavior and Speeding Behavior scales, respectively. The internal consistency reliability for the overall measure is .80 (Houston, Harris, \& Norman, 2003, p. 272). The overall alpha coefficient observed for this study's sample was .84 .

Alcohol Use. Two questions were designed to capture the frequency of alcohol use. The first question was "How often, on average, do you usually drink alcoholic beverages?" Responses ranged from $1=$ Never to $6=$ Every day. The second question was "When you do drink alcoholic beverages, how many beverages do you usually drink at one time?" Responses ranged from $1=\mathrm{I}$ Do Not Drink to $5=7$ or More Drinks. Higher scores indicated a greater likelihood of engaging in alcohol use. A coefficient alpha has yet to be achieved for this measure because the scale was created especially for this study and has not been used in previous studies. The internal consistency estimate observed for this study's sample was .80 . 
Competitiveness. The Competitive subscale of the Cooperative/Competitive Strategy Scale (Simmons, Wehner, Tucker, \& King, 1988) was used to assess competitiveness of individuals. The purpose of the scale is to measure positive and negative attitudes toward success and toward competitive and cooperative success strategies. As a result, the scale includes items that describe both positive and negative attitudes toward competition. Participants are asked to respond to 11 items on a 5-point scale $(1=$ Never, $2=$ Rarely, $3=$ Sometimes, $4=$ Usually, and $5=$ Always $)$. Sample items include: "It is important to do better than others," "To succeed, one must compete against others," "I enjoy the challenge of competing against others to succeed," and "I feel better about myself when I am working toward success." The internal consistency of the Competitive subscale is .84 (Simmons et al., 1988, p. 204). The overall alpha coefficient observed for this study's sample was .81.

Agreeableness. The 10-item Agreeableness scale of the International Personality Item Pool (IPIP; Goldberg, 1999) was used to measure a participant's level of agreeableness. The IPIP is a nonproprietary measure of personality that is designed to assess the five major dimensions of personality (i.e., Conscientiousness, Openness to Experience, Extraversion, Agreeableness, and Neuroticism). Participants are asked to indicate on a 5 -point scale how well each item describes them $(1=$ Very Inaccurate, $2=$ Moderately Accurate, 3 = Neither Accurate/Nor Inaccurate, 4 = Moderately Accurate, and $5=$ Very Accurate). Sample items include: "I sympathize with others' feelings," "I take time out for others," "I feel others' emotions," and "I have a soft heart." The internal consistency of the overall Agreeableness scale is .82 (Goldberg, 1999). The overall alpha coefficient observed for this study's sample was .86 . 
Socially Desirable Response Bias (SDRB). The Balanced Inventory of Desirable Responding (BIDR; Paulhus, 1984, 1991) was used to detect socially desirable response bias. The BIDR is a 40-item assessment that is used to measure two constructs: SelfDeception (20 items) and Impression Management (20 items). Self-Deception occurs when a respondent actually believes his or her positive self-reports; it is a dispositional tendency to think of oneself in a favorable light. Impression Management occurs when a respondent consciously attempts to distort their responses in order to create a favorable impression with others. People who score high on the BIDR are said to be altering their responses to appear more favorable. Respondents are asked to rate their level of agreement on a 7 -point scale $(1=$ Not True, $4=$ Occasionally True, and $7=$ Very True $)$. The coefficient alpha for the overall measure is .83 and the internal consistency range for Self-Deception and Impression Management are .68-.80 and .75-.86, respectively (Paulhus, 1988). Test-retest correlations over a 5-week period were reported as being .69 and .65 for Self-Deception and Impression Management, respectively (Paulhus, 1988). The overall alpha coefficient observed for this study's sample was .86 .

Demographics. The following participant demographics were collected by selfreport: gender, age, whether or not they were a first semester Freshman, race/ethnicity, and cumulative grade point average (GPA). 


\section{CHAPTER IV}

\section{RESULTS}

In this chapter, I will detail the statistical analyses performed and will summarize the results of the current study. For Hypotheses 1 through 5, a series of bivariate correlations were performed to examine the relationship between each predictor (i.e., CRT-A, BPAQ, and new aggression scale) with each criterion variable. A positive relationship was hypothesized between each predictor and violent acts, traffic violations, alcohol use, and competitiveness (Hypotheses 1 - 4) and a negative relationship was hypothesized for agreeableness (Hypothesis 5). Table 1 provides a summary of the sample sizes, means, standard deviations, and correlations for all of the study variables. Additionally, after controlling for demographics and SDRB (Tables 2 - 6), the results revealed that the relationships between all predictors and criteria were in the hypothesized direction (except for violent acts which was negatively, yet insignificantly, related to the new measure; $\beta=-.038$ ). In general, aggression is positively related to violent acts, traffic violations, alcohol use, and competitiveness and negatively related to agreeableness. Thus, the data provide support for Hypotheses 1 through 5.

Although each predictor measure had the hypothesized directional relationship with the criteria, not all predictors were significantly correlated. The CRT-A was not significantly correlated with any of the five criterion variables. The BPAQ was significantly correlated with four out of the five criterion variables with a $p<.001$ for violent acts $(r=.363)$, traffic violations $(r=.340)$, and agreeableness $(r=-.297)$ and a $p$ $<.01$ for competitiveness $(r=.170)$. The new measure of aggression was significantly correlated with all of the five criterion variables with a $p<.001$ for violent acts $(r=$ 
Table 1.

Summary of Sample Sizes, Means, Standard Deviations, and Correlations for All Study Variables

\begin{tabular}{|c|c|c|c|c|c|c|c|c|c|c|c|c|c|c|c|c|c|}
\hline Variables & $N$ & $M$ & $S D$ & 1 & 2 & 3 & 4 & 5 & 6 & 7 & 8 & 9 & 10 & 11 & 12 & 13 & 14 \\
\hline \multicolumn{18}{|l|}{ Time 1} \\
\hline 1 CRT-A & 274 & 4.57 & 2.19 & - & & & & & & & & & & & & & \\
\hline 2 BPAQ & 269 & 2.52 & .64 & .107 & $(.89)$ & & & & & & & & & & & & \\
\hline 3 New Measure & 266 & 3.84 & .80 & $.145^{*}$ & $.555^{* * *}$ & $(.89)$ & & & & & & & & & & & \\
\hline \multicolumn{18}{|l|}{ Time 2} \\
\hline 4 Gender & 273 & .68 & .47 & -.088 & -.075 & $-.176^{* *}$ & - & & & & & & & & & & \\
\hline 5 Age & 272 & 20.77 & 4.34 & .074 & -.046 & -.108 & $-.123^{*}$ & - & & & & & & & & & \\
\hline $61^{\text {st }}$ Semester Freshman & 273 & .33 & .47 & .025 & .088 & .047 & .056 & $-.430^{* *}$ & - & & & & & & & & \\
\hline 7 Race/Ethnicity & 273 & .71 & .46 & -.006 & -.048 & -.045 & .118 & -.054 & -.045 & - & & & & & & & \\
\hline 8 GPA & 272 & 3.65 & .54 & -.104 & -.001 & -.079 & $.167^{* *}$ & $-.189^{* *}$ & $.250^{* *}$ & -.010 & - & & & & & & \\
\hline $9 \mathrm{SDRB}$ & 221 & 13.67 & 6.94 & -.007 & $-.267^{* *}$ & $-.295^{* *}$ & .061 & .010 & .081 & .081 & .076 & $(.86)$ & & & & & \\
\hline 10 Violent Acts & 266 & 1.40 & .62 & .061 & $.363^{* *}$ & $.238^{* *}$ & $-.123^{*}$ & -.024 & .037 & -.105 & -.092 & $-.361^{* *}$ & $(.91)$ & & & & \\
\hline 11 Traffic Violations & 260 & 2.50 & .77 & .062 & $.340^{* *}$ & $.340^{* *}$ & -.051 & -.075 & -.041 & .013 & -.051 & $-.268^{* *}$ & $.290^{* *}$ & $(.84)$ & & & \\
\hline 12 Alcohol Use & 273 & 2.79 & 1.15 & .055 & .087 & $.121^{*}$ & -.037 & .113 & $-.208^{* *}$ & .090 & $-.183^{* *}$ & -.095 & .007 & $.267^{* *}$ & $(.80)$ & & \\
\hline 13 Competitiveness & 267 & 3.84 & .55 & .024 & $.170^{* *}$ & $.131^{*}$ & -.036 & $-.173^{* *}$ & .025 & -.031 & .030 & .078 & .015 & $.150^{*}$ & .073 & $(.81)$ & \\
\hline 14 Agreeableness & 262 & 4.03 & .66 & -.106 & $-.297^{* *}$ & $-.280^{* *}$ & $.171^{* *}$ & .012 & .026 & .056 & -.011 & $.291^{* *}$ & $-.262^{* *}$ & $-.166^{* *}$ & .006 & -.015 & $(.86)$ \\
\hline
\end{tabular}

Note. 1. CRT-A = Conditional Reasoning Test of Aggression. 2. BPAQ = Buss-Perry Aggression Questionnaire. 3. New Measure Built on JMs. 4. Gender $(0=$ Male, $1=$ Female $)$. 5. Age. 6. $1^{\text {st }}$ Semester Freshman. $(0=$ No, $1=$ Yes $)$ 7. Race $/$ Ethnicity $(0=$ Non-Hispanic, $1=$ Hispanic $)$ 8. GPA = Grade Point Average (Cumulative). 9. SDRB = Socially Desirable Response Bias. Alpha coefficients are presented along the diagonal in parenthesis.

* Correlation is significant at the 0.05 level (2-tailed).

** Correlation is significant at the 0.01 level (2-tailed).

*** Correlation is significant at the .001 level (2-tailed). 
$.238)$, traffic violations $(r=.340)$, and agreeableness $(r=-.280)$ and a $p<.05$ for alcohol use $(r=.121)$ and competitiveness $(r=.131)$. The possible reasoning for these relationships will be discussed further in the following chapter.

For Exploratory Analysis 1, the objective was to investigate the relationship between the three predictors amongst themselves. Because each predictor theoretically measures different aspects of aggression, it was expected that each would differentially relate to one another. As presented in Table 1, bivariate correlations show that the new measure was significantly correlated with the CRT-A $(r=.145, p<.05)$ and BPAQ $(r=$ $.555, p<.001)$ while the correlation between the CRT-A and BPAQ was non-significant $(r=.107, n s)$. Using Fisher's $z$-transformation formula, the correlation between the BPAQ and new measure $(r=.555)$ was significantly greater than the correlation between the CRT-A and BPAQ $(r=.107), z=5.96, p<.001$. The correlation between the BPAQ and new measure $(r=.555)$ was significantly greater than the correlation between the CRT-A and new measure $(r=.145), z=5.49, p<.001$. Lastly, the correlation between the CRT-A and new measure $(r=.145)$ was not significantly different from the correlation between the CRT-A and BPAQ $(r=.107), z=.44, n s$. Altogether these findings suggest that the new measure is more closely related to the BPAQ than it is to the CRT-A.

Another way of looking at these relationships is by examination of shared variance. The shared variance between the new measure and the CRT-A was $2 \%$ and the shared variance between the new measure and the BPAQ was 31\%. Therefore, despite being significant, the correlation between the new measure and CRT-A was minimal and implies little overlap between the two measures. Further illustrating this point was the 
non-significant difference in correlations between the CRT-A with the BPAQ $(r=.107)$ and the CRT-A with the new measure $(r=.145)$. Essentially, the new measure did not relate to the CRT-A any better than the (non-significant) relationship observed between the CRT-A and BPAQ. On the other hand, the correlation between the new measure and the BPAQ can be described as moderate to moderately high, suggesting that they are not highly correlated enough to be measuring the same aspects of aggression.

To test Exploratory Analyses 2 and 3, moderated hierarchical multiple regressions were used (MHMR; Aiken \& West, 1991; Bing et al., 2007; Cohen \& Cohen, 1983). The focus of these regressions were on incremental main and interaction effects that the predictors had on violent acts, traffic violations, alcohol use, competitiveness, and agreeableness, above and beyond the demographic variables and SDRB. Demographic variables and SDRB were entered at Step 1. To determine incremental variance, the main effects of the three aggression measures were entered at Step 2. Lastly, at Step 3, interaction terms were entered with one interaction being tested at a time for a total of three separate regressions (i.e., 3a. CRT-A x BPAQ; 3b. CRT-A x New Measure Built on JMs; and 3c. BPAQ x New Measure Built on JMs). Accordingly, MHMR assessed whether the interaction term entered in Step 3 made a unique contribution to the explanation of variance in the criteria above and beyond the controls (gender, race/ethnicity, age, first semester Freshman, GPA, and SDRB) and main effects of the predictors (CRT-A, BPAQ, and new measure built on JMs). In sum, three 3-step regression analyses were run for each of the five criterion variables for a grand total of 15 regressions. The results revealed that there were no significant interactions except for one 
between the BPAQ and new measure on competitiveness with a change in $R^{2}=.022, F$ $(1,204)=5.144, p<.05$.

Figure 1.

BPAQx New Measure Built on JMs Interaction Effect on Competitiveness

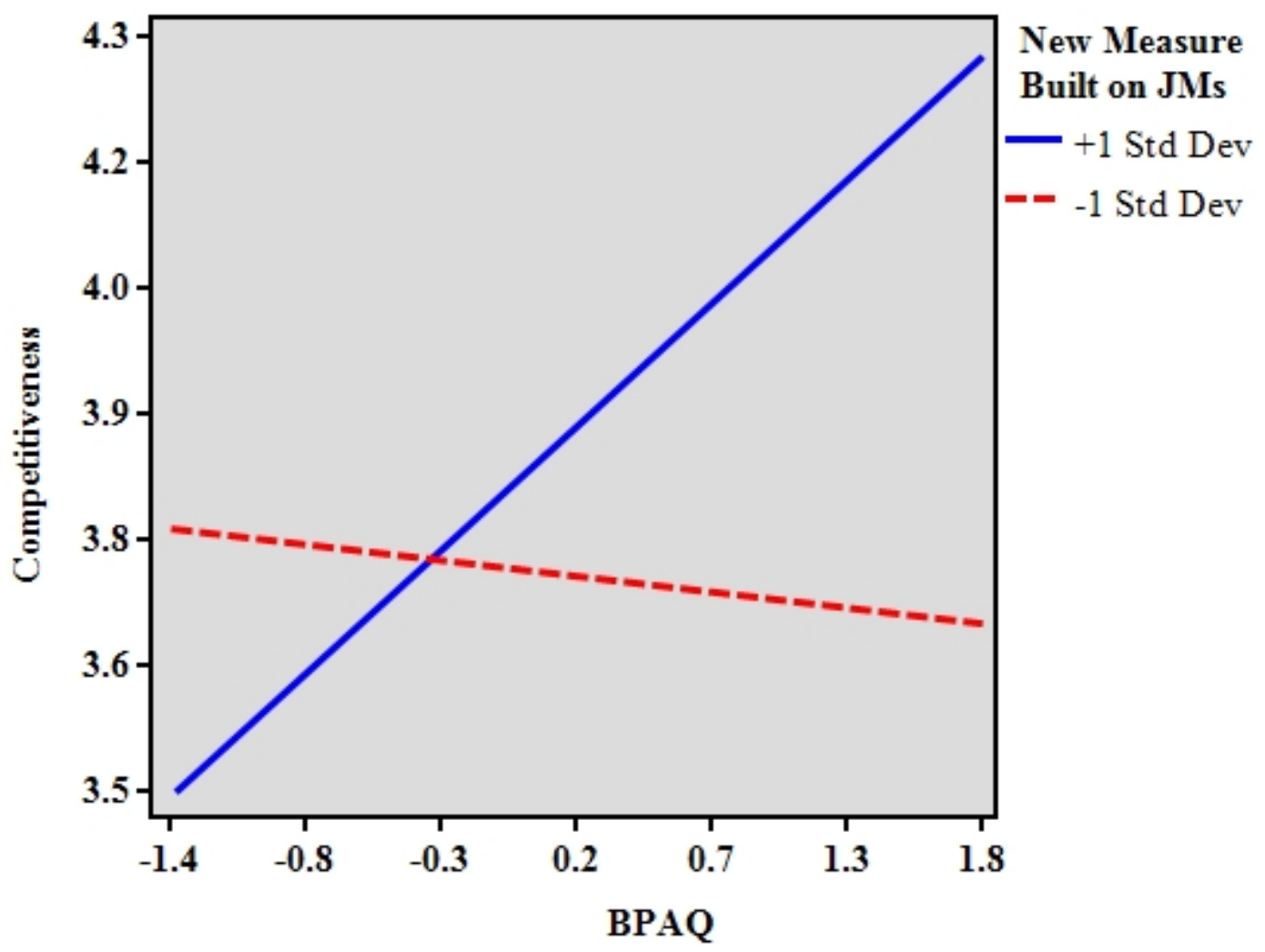

Note: $\mathrm{BPAQ}=$ Buss-Perry Aggression Questionnaire.

Following procedures recommended by Aiken and West (1991), all interaction terms were created by centering each variable involved in the interaction. By centering variables it helps to alleviate concerns of multicollinearity which is when two or more predictor variables in a multiple regression model are highly correlated. Following procedures recommended by Cohen and Cohen (1983), Figure 1 shows the graphed relationship between BPAQ and competitiveness using scores on the newly developed 
aggression measure at high and low levels - using 1 standard deviation above and below the mean (see also Aiken \& West, 1991, Bing et al., 2007). Interactions are graphed using centered variables.

\section{Effects of Predictor Measures on Violent Acts}

As displayed in Table 2, after controlling for demographics and SDRB, the three aggression measures accounted for significant incremental variance in violent acts $\left(\Delta R^{2}=\right.$ $.070, p<.001)$. The BPAQ was the strongest predictor of violent acts $(\beta=.293, p<.001)$ while the CRT-A and the new measure built on JMs were not significantly predictive.

Lastly, none of the three interaction terms accounted for significant incremental variance over and above the main effects.

\section{Table 2.}

Moderated Regression Analyses Examining the Main and Interaction Effects of Each Aggression Measure on Violent Acts

\begin{tabular}{llcc}
\hline Ordered Predictors & $B$ & $R^{2}$ & $\Delta R^{2}$ \\
\hline & & & \\
1. Gender & -.088 & .156 & $.156^{* * *}$ \\
Age & -.015 & & \\
$1^{\text {st }}$ Semester Freshman & .078 & & \\
Race/Ethnicity & -.064 & & \\
GPA & -.073 & & \\
SDRB & $-.352^{* * *}$ & & $.070^{* * *}$ \\
& & & \\
2.CRT-A & .013 & .226 & \\
BPAQ & $.293^{* * *}$ & & .000 \\
New Measure Built on JMs & -.038 & & .001 \\
3a. CRT-A x BPAQ & & .012 & .226 \\
3b. CRT-A x New Measure Built on JMs & -.033 & .227 & .001 \\
3c. BPAQ x New Measure Built on JMs & .032 & .227 \\
\hline
\end{tabular}

Note. $N=215$. Three 3 -step moderated regressions were performed, one for each interaction term (3a, 3b, $3 c)$. GPA = Grade Point Average (Cumulative). SDRB = Socially Desirable Response Bias. CRT-A = Conditional Reasoning Test of Aggression. BPAQ = Buss-Perry Aggression Questionnaire. $\beta$ s are from corresponding first, second, and third steps.

$* * * p<.001$. 


\section{Effects of Predictor Measures on Traffic Violations}

In Table 3, after controlling for demographics and SDRB, the three aggression measures accounted for significant incremental variance in traffic violations $\left(\Delta R^{2}=.098\right.$, $p<.001)$. The BPAQ was the most strongly predictive of traffic violations $(\beta=.207, p<$ $.01)$ followed by the new measure built on JMs $(\beta=.173, p<.05)$. The CRT-A was not significantly predictive of traffic violations when included with the other two measures of aggression. Lastly, none of the three interaction effects accounted for significant incremental variance over and above the main effects.

Table 3.

Moderated Regression Analyses Examining the Main and Interaction Effects of Each Aggression Measure on Traffic Violations

\begin{tabular}{llll}
\hline Ordered Predictors & $B$ & $R^{2}$ & $\Delta R^{2}$ \\
\hline & & & \\
1. Gender & -.044 & .086 & $.086^{* *}$ \\
Age & -.102 & & \\
$1^{\text {st }}$ Semester Freshman & -.051 & & \\
Race/Ethnicity & .030 & & \\
GPA & -.031 & & \\
SDRB & $-.266^{* * *}$ & & $.098^{* * *}$ \\
& & & \\
2. CRT-A & .008 & .185 & \\
BPAQ & $.207^{* *}$ & & .007 \\
New Measure Built on JMs & $.173^{*}$ & & .005 \\
3a. CRT-A x BPAQ & .082 & .191 & .004 \\
3b. CRT-A x New Measure Built on JMs & .072 & .189 & \\
3c. BPAQ x New Measure Built on JMs & .066 & .189 & \\
\hline
\end{tabular}

Note. $N=212$. Three 3-step moderated regressions were performed, one for each interaction term ( $3 \mathrm{a}, 3 \mathrm{~b}$, 3c). GPA = Grade Point Average (Cumulative). SDRB = Socially Desirable Response Bias. CRT-A = Conditional Reasoning Test of Aggression. BPAQ = Buss-Perry Aggression Questionnaire. $\beta$ s are from corresponding first, second, and third steps.

$* p<.05 ; * * p<.01 ; * * * p<.001$. 


\section{Effects of Predictor Measures on Alcohol Use}

In Table 4, after controlling for demographics and SDRB, the three aggression measures did not account for significant incremental variance in alcohol use.

Consequently, because there were no main effects found, there were also no interaction effects either.

Table 4.

Moderated Regression Analyses Examining the Main and Interaction Effects of Each Aggression Measure on Alcohol Use

\begin{tabular}{lccc}
\hline Ordered Predictors & $B$ & $R^{2}$ & $\Delta R^{2}$ \\
\hline 1. Gender & -.011 & .076 & $.076^{*}$ \\
Age & .033 & & \\
$1^{\text {st }}$ Semester Freshman & -.144 & & \\
Race/Ethnicity & .089 & & \\
GPA & -.134 & & \\
SDRB & -.091 & & .014 \\
& & .090 & \\
2. CRT-A & .024 & & \\
BPAQ & .046 & & .000 \\
New Measure Built on JMs & .089 & .090 & .006 \\
3a. CRT-A x BPAQ & -.007 & .096 & .009 \\
3b. CRT-A x New Measure Built on JMs & .081 & .099 & \\
3c. BPAQ x New Measure Built on JMs & .098 & & \\
\hline
\end{tabular}

Note. $N=215$. Three 3-step moderated regressions were performed, one for each interaction term (3a, $3 \mathrm{~b}$, 3c). GPA $=$ Grade Point Average (Cumulative). SDRB $=$ Socially Desirable Response Bias. CRT-A = Conditional Reasoning Test of Aggression. BPAQ = Buss-Perry Aggression Questionnaire. $\beta$ s are from corresponding first, second, and third steps.

$* p<.05$.

\section{Effects of Predictor Measures on Competitiveness}

In Table 5, after controlling for demographics and SDRB, the three aggression measures accounted for significant incremental variance in competitiveness $\left(\Delta R^{2}=.040\right.$, $p<.05$ ). As mentioned previously, one of the three interaction terms (i.e., BPAQ x New Measure Built on JMs) accounted for significant incremental variance over and above the 
main effects, $\Delta R^{2}=.022, F(1,204)=5.144, p<.05$. Figure 1 displays the interaction effect of the BPAQ and new measure in regards to competitiveness. The graph illustrates the positive relationship between the BPAQ and competitiveness is stronger for those scoring higher on the new measure. In other words, more competitive individuals are those not only explicitly reporting aggressive behaviors (i.e., higher scores on the BPAQ) but they are those also holding more JMs for aggression (i.e., scoring higher on the new measure).

Table 5.

Moderated Regression Analyses Examining the Main and Interaction Effects of Each Aggression Measure on Competitiveness

\begin{tabular}{llll}
\hline Ordered Predictors & $\beta$ & $R^{2}$ & $\Delta R^{2}$ \\
\hline & & & .046 \\
1. Gender & -.061 & .046 & \\
Age & $-.213^{* *}$ & & \\
$1^{\text {st }}$ Semester Freshman & .073 & & \\
Race/Ethnicity & -.047 & & \\
GPA & .009 & & $.040^{*}$ \\
SDRB & .091 & \\
2. CRT-A & .009 & .085 & \\
BPAQ & $.176^{*}$ & & .004 \\
New Measure Built on JMs & .053 & .009 \\
& & & $.022^{*}$ \\
3a. CRT-A x BPAQ & -.062 & .089 & \\
3b. CRT-A x New Measure Built on JMs & -.097 & .094 & \\
3c. Gender & -.043 & .108 & \\
Age & $-.198^{* *}$ & & \\
$1^{\text {st }}$ Semester Freshman & -.093 & \\
Race/Ethnicity & -.042 & \\
GPA & .012 & \\
SDRB & $.141^{*}$ & & \\
CRT-A & .015 & \\
BPAQ & .146 & \\
New Measure Built on JMs & .082 & \\
BPAQ x New Measure Built on JMs & $.154^{*}$ & \\
\hline
\end{tabular}

Note. $N=215$. Three 3 -step moderated regressions were performed, one for each interaction term ( $3 \mathrm{a}, 3 \mathrm{~b}$, 3c). GPA = Grade Point Average (Cumulative). SDRB = Socially Desirable Response Bias. CRT-A = Conditional Reasoning Test of Aggression. BPAQ = Buss-Perry Aggression Questionnaire. $\beta$ s are from corresponding first, second, and third steps.

$* p<.05 ; * * p<.01$. 


\section{Effects of Predictor Measures on Agreeableness}

In Table 6, after controlling for demographics and SDRB, the three aggression measures accounted for significant incremental variance in agreeableness $\left(\Delta R^{2}=.059, p\right.$ $<.01)$. The BPAQ was the strongest predictor of agreeableness $(\beta=-.176, p<.05)$ while the CRT-A and the new measure built on JMs were not significantly predictive. Lastly, none of the three interaction terms accounted for significant incremental variance over and above the main effects.

Table 6.

Moderated Regression Analyses Examining the Main and Interaction Effects of Each Aggression Measure on Agreeableness

\begin{tabular}{llll}
\hline Ordered Predictors & $\beta$ & $R^{2}$ & $\Delta R^{2}$ \\
\hline 1. Gender & & & $.117^{* * *}$ \\
Age & $.165^{*}$ & .117 & \\
$1^{\text {st }}$ Semester Freshman & .026 & & \\
Race/Ethnicity & .018 & & \\
GPA & .016 & & \\
SDRB & -.059 & & $.059^{* *}$ \\
& $.289^{* * *}$ & & \\
2. CRT-A & & & \\
BPAQ & -.064 & .176 & \\
New Measure Built on JMs & $-.176^{*}$ & & .000 \\
& -.091 & & .001 \\
3a. CRT-A x BPAQ & .070 & .176 & .000 \\
3b. CRT-A x New Measure Built on JMs & .030 & .177 & .176 \\
3c. BPAQ x New Measure Built on JMs & .008 & & \\
\hline
\end{tabular}

Note. $N=215$. Three 3-step moderated regressions were performed, one for each interaction term (3a, $3 \mathrm{~b}$, $3 c$ ). GPA = Grade Point Average (Cumulative). SDRB = Socially Desirable Response Bias. CRT-A = Conditional Reasoning Test of Aggression. BPAQ = Buss-Perry Aggression Questionnaire. $\beta$ s are from corresponding first, second, and third steps.

$* p<.05 ; * * p<.01 ; * * * p<.001$.

Overall, in reference to Exploratory Analyses 1 - 3, the results revealed that there was greater overlap between the new measure with the BPAQ than with the CRT-A. Also there was a non-significant, low correlation between the BPAQ with the CRT-A. With 
the MHMR analyses, the BPAQ was the strongest predictor of each criterion, except for alcohol use which resulted in no predictor measures being significantly predictive. The incremental variance of all three aggression measures after controlling for demographics and SDRB, ranged from $1.4 \%(n s)$ for alcohol use to $9.8 \%(p<.001)$ for traffic violations. Interestingly, the CRT-A was not significantly predictive in any of the regression analyses; standardized beta coefficients ranged from .008 for traffic violations to -.064 for agreeableness. Lastly, only one interaction term was found between the BPAQ and new measure with the prediction of competitiveness. This suggests that given a particular sample, implicit and explicit cognitions may interact to predict only a certain type of criterion and not others. The possible reasons for these findings will be discussed in the following section. 


\section{CHAPTER V}

\section{DISCUSSION}

This thesis was designed to extend previous research on aggressive personality by examining how a newly developed aggression measure relates to an explicit self-report and an implicit conditional reasoning test of aggression. Additionally, it examined the validity of the new measure as a predictor of theoretically-related criteria. The results provide insight into the usefulness of the new measure and how it can be used in future research endeavors. Overall, hypothesized directional relationships were found between aggressiveness and violent acts, traffic violations, alcohol use, competitiveness, and agreeableness. The results revealed, on average, aggressive individuals commit more violent acts, engage in more traffic violations, consume more alcohol, prefer competition, and are less agreeable. Besides the proposed relationships in Hypotheses 1 through 5, this study was largely exploratory in order to see how well the new measure would do when put to the test. The literature shows the need for examining both the explicit and implicit components of personality (e.g., Bing et al., 2007), however, having a self-report that actually taps into implicit cognitions (i.e., operationalizes aggression as JMs) is lacking. Thus, without ever attempting to do such research, researchers would never know if this technique is a viable option within personality testing.

One of the main reasons for developing a self-report built from conditional reasoning JMs was to have a short and inexpensive way to measure implicit personality. Today, organizations are concerned with the economic bottom-line and the most effective way to achieve goals without using excess time, personnel, and resources. Thus, this was the impetus for creating a measure that would potentially tap into the rationalization 
process of personality in a quick and easy manner. The argument is that this new method is not your typical self-report because it does not ask respondents to answer items based directly on the variable of interest, in this case, aggression. Instead, the new measure poses brief statements based on JMs and asks participants to rate how well he/she agrees or disagrees with each. The new measure was intentionally designed to tap into underlying reasons for behaving aggressively and are, in fact, built from the same JMs as the CRT-A. But, as Greenwald and Banaji (1995) noted, implicit measures "neither inform the subject of what is being assessed nor request self-report concerning it” (p. 5). As such, the new measure does not qualify as a conditional reasoning measure simply because it asks participants to self-report. But, on the other hand, it does resemble the conditional reasoning approach in that items are based on the logical reasoning for behaving one way over another (i.e., justification mechanisms) and do not look to directly cue respondents in to the variable of interest.

The results revealed that the new measure had a moderate to moderately high correlation with the BPAQ and a low correlation with the CRT-A. These correlations suggest that despite being created from the same JMs, the new measure is not assessing the same aspects of aggression as the CRT-A and is more closely related to the BPAQ. Post hoc analyses reveal that the CRT-A was significantly correlated with only two of the six facets (i.e., JMs) of the new measure, they were Hostile Attribution Bias $(r=.168, p$ $<.01)$ and Victimization by Powerful Others Bias $(r=.172, p<.01)$. In contrast, the BPAQ was significantly correlated with all six facets of the new measure at $p<.001$; Hostile Attribution Bias $(r=.379)$, Potency Bias $(r=.347)$, Retribution Bias $(r=.532)$, 
Victimization by Powerful Others Bias $(r=.372)$, Derogation of Target Bias $(r=.281)$, and Social Discounting Bias $(r=.359)$.

As was previously mentioned, James and colleagues (2004) constructed a similar self-report built from JMs and obtained a correlation of .17 $(p<.01)$ with their Conditional Reasoning-Aggression scale. Although different results were anticipated, this study reproduced the same low correlation between the two measures with only $3.6 \%$ of the variance in the CRT-A explained by the new measure. On the other hand, as much as the BPAQ and new measure are correlated, they are not strongly correlated enough to say that they are measuring exactly the same aspects of aggression. These findings reaffirm what is currently being said in the literature. There is significant difference between implicit and explicit cognitions (Bornstein, 2002; Brewin, 1989; Epstein, 1994; Fazio \& Olson, 2003; Greenwald \& Banaji, 1995; Hogan, 1991; James, 1998; LeBreton, Binning, \& Adorno, 2006; McClelland et al., 1989; Mischel \& Shoda, 1995; Spangler, 1992; Westen, 1998; Winter et al., 1998). Specifically, as McClelland and colleagues (McClelland, 1985; McClelland et al., 1989) found, when implicit and explicit personality cognitions are measured they are often uncorrelated and are likely to interact when predicting various criteria. To address this notion, Exploratory Analyses 2 and 3 investigated each of the predictor measures, uniquely and in combination, as they related to the criterion variables.

Interestingly, the CRT-A was the only predictor not significantly correlated with any of the criterion variables. At first, it was believed that the low base rate of aggression scores affected the bivariate correlations and, in turn, the predictive validity of the CRTA. However, the frequency distribution of scores in this study matched that of the sample 
Table 7.

Frequency Distribution of Scores for the CRT-A

\begin{tabular}{|c|c|c|c|}
\hline $\begin{array}{c}\text { CRT-A } \\
\text { Score }\end{array}$ & Frequency & Percent & $\begin{array}{c}\text { Cumulative } \\
\text { Percent }\end{array}$ \\
\hline 0 & 1 & .4 & .4 \\
1 & 17 & 6.2 & 6.6 \\
2 & 30 & 10.9 & 17.5 \\
\hline 3 & & & \\
4 & 51 & 18.6 & 52.9 \\
5 & 43 & 15.7 & 68.6 \\
6 & 34 & 12.4 & 81.0 \\
7 & 25 & 9.1 & 90.1 \\
& & & \\
\hline 8 & 15 & 5.5 & 95.6 \\
9 & 6 & 2.2 & 97.8 \\
10 & 3 & 1.1 & 98.9 \\
11 & 2 & .7 & 99.6 \\
12 & 1 & .4 & $\mathbf{1 0 0 . 0}$ \\
Total & $\mathbf{2 7 4}$ & $\mathbf{1 0 0 . 0}$ & \\
\hline & & & \\
\hline
\end{tabular}

Note. Scores ranging from 0 -2 represent low aggression, 3-7 represent moderate aggression, and 8 or more represent high aggression.

distribution of scores presented in the CRT-A test manual (James \& McIntyre, 2000). As indicated by James and McIntyre (2000), the theoretical range of aggression scores is 0 (i.e., picking none of the aggressive answers) to 22 (i.e., picking all of the aggressive answers). However, "even the most aggressive respondents rarely select more than onehalf of the aggressive answers" (James \& McIntyre, 2000, p. 24) and as a result, the practical range of scores on the CRT-A is closer to 0 to 12 , with scores of 8 or more representing high aggression. In Table 7, the frequency distribution of the CRT-A scores for this study is presented. The range was from 0 to 12 with $10 \%$ of participants scoring 8 
or more. This observed percentage is supported by James and McIntyre's (2000) assertion that $8-12 \%$ of respondents are considered strongly aggressive and the vast majority of participants are moderately aggressive (i.e., scoring between 3 and 7).

With a low base rate for aggression ruled out, another possibility for why the CRT-A was not significantly correlated with any of the criterion variables may be attributed to the very nature of the CRT-A and criteria themselves. The main purpose of the CRT-A is to assess the "cognitive readiness to aggress" (James \& McIntyre, 2000). Therefore, by tapping into implicit reasoning and motives, the CRT-A would better predict subtle, indirect criteria unlike the criteria used in this study. Social psychology literature on implicit and explicit attitudes states that implicit attitudes should predict primarily behaviors that are not consciously monitored or that are difficult to control (e.g., facial expressions, eye contact, blushing, and other nonverbal behaviors), as well as less blatant behaviors (i.e., in this case, passive aggressiveness; Ajzen \& Fishbein, 2005). Thus, some alternative criteria for this study could have been gossiping or spreading rumors, withholding pertinent information from team members, absenteeism or tardiness, reactions to aggressive scenarios, or perceptions of other people's intentions.

On the other hand, behaviors that are based on choice and are more apparent should be better predicted by explicit measures than implicit ones (Ajzen \& Fishbein, 2005). Although James and McIntyre (2000) claim that the CRT-A theoretically predicts extreme forms of aggression (e.g., physical attacks, assault, and murder), little empirical research has focused on such criteria. For instance, validation studies for the CRT-A primarily focused on passive aggression and indirect operationalizations of aggression. One study looked at the performance ratings of patrol officers and their individual level 
of aggression (James \& McIntyre, 2000). It was hypothesized that aggressive officers (i.e., those scoring high on the CRT-A) would receive lower performance ratings because of a natural tendency to frame minor infractions by citizens as intentional defiance against authority and the law. Such framing would increase the likelihood of unfair, hostile treatment of offenders and would in turn lead to complaints. In another study, James and McIntyre (2000) operationalized an individual's aggressiveness by whether or not they misrepresented the amount of extra credit earned for participation in a stressinduced study. It was hypothesized that aggressive students would be angered by the study and would in turn "get even" or "retaliate" by increasing the amount of extra credit earned for participation. In both of these studies the hypotheses were supported. Thus, these results suggest that implicit predictors (e.g., the CRT-A) are better able to predict passive and indirect operationalizations of aggression. Alternatively, explicit predictors (e.g., the BPAQ and new measure) are better able to predict active and direct operationalizations of aggression. This study extends previous literature on the construct and criterion-related validity of the CRT-A, however, future research is still needed to address this phenomenon further.

Consistent with the literature on socially desirable response bias, it is an important variable to control for when testing antisocial personality traits such as aggressiveness and behaviors such as violent acts and traffic violations. The present study revealed that both the BPAQ and new measure were significantly correlated with SDRB. The negative relationship between SDRB and the two measures indicate that, on average, as participants score higher on aggressiveness they also score lower on SDRB. Intuitively speaking, participants with lower aggression scores are said to be more inclined to engage 
in SDRB. Hence, controlling for SDRB in the regression analyses was a valuable precaution included in this study. Alternatively, the results show a negligible correlation between SDRB and the CRT-A $(r=-.012)$ which is similar to the results of previous studies addressing the implicit methodology (e.g., LeBreton et al., 2007). Despite being non-significant, the strength of the correlation indicates that scores on the CRT-A are not as likely to be influenced by an individual's tendency to engage in socially desirable response bias. One point that could be reiterated here is that the new measure, although developed from implicit justifications for behaving aggressively, is yet again more comparable with the BPAQ (i.e., susceptible to SDRB).

The ability for an individual to consciously fake a measure of implicit cognitions calls into question the very nature of the measure to assess unconscious cognitions (cf. Holmes, 1974; Orpen, 1978). That is, if respondents can consciously manipulate their scores on the test, then the test likely is not measuring unconscious cognitions. This logic in combination with the observed correlations suggests that while the new measure is not necessarily measuring implicit cognitions, it is not exactly measuring factors of the BPAQ either. The question then posed is what aspect of aggression is being captured by the new measure. Post hoc analyses revealed that the CRT-A was significantly correlated to only two of the six facets of the new measure. These two facets were Hostile Attribution Bias $(r=.168, p<.01)$ and Victimization by Powerful Others Bias $(r=.172$, $p<.01)$. Thus, is the new measure a mixture of the CRT-A and BPAQ? For example, is it measuring an individual's propensity to justify aggression as opposed to measuring the actual behavior itself? Is it capturing an individual's self-reported reasoning ability to rationalize traits and behaviors deemed antisocial? Or is it measuring an individual's 
tolerance level for aggression when the rationale behind the behavior is convincing enough? These are just a few viable questions that can be addressed in future research studies.

In reference to all of the study demographics, there were no significant correlations with any of the predictor measures except for one. There was a significant correlation between gender and the new measure where males scored higher, on average, than females. This finding was surprising considering that the other two measures of aggression (i.e., the CRT-A and BPAQ) did not have similar results. However, a further look at the facet-level of the new measure revealed that out of all facets, only two of the six were significantly correlated with gender. These two facets were Victimization by Powerful Others Bias and Social Discounting Bias. For Victimization by Powerful Others Bias, there was a statistically significant difference in means between male and female respondents, $t(268)=-3.73, p<.001$, with males $(M=4.63, S D=1.03)$ scoring higher than females $(M=4.10, S D=1.13)$. For Social Discounting Bias, there was a statistically significant difference in means between male and female respondents, $t(269)=-3.02, p$ $<.01$, with males $(M=3.98, S D=.97)$ scoring higher than females $(M=3.58, S D=$ $1.05)$.

Altogether, gender differences in the new measure are attributed to males holding more JMs for aggression as a correction of inequalities and strikes against oppression by authority figures (e.g., parents, teachers, supervisors, law enforcers, and institutions such as universities and employers; i.e., Victimization by Powerful Others). Also, males hold greater contempt for traditional ideals and social regulations than do females (i.e., Social Discounting Bias). In other words, these results suggest that males in comparison to 
females are more likely to endorse aggressive JMs for feeling oppressed by others and social customs. Could this be attributed to gender role schemas that are at play in our society? Logically speaking, this makes sense because research shows that men ascribe to agentic characteristics and women to communal characteristics. Agentic characteristics “describe primarily an assertive, controlling, and confident tendency - for example, aggressive, ambitious, dominant, forceful, independent, self-sufficient, self-confident, and prone to act as a leader" (Eagly \& Karau, 2002). In contrast, communal characteristics "describe primarily a concern with the welfare of other people - for example, affectionate, helpful, kind, sympathetic, interpersonally sensitive, nurturant, and gentle" (Eagly \& Karau, 2002). Therefore, if males feel as though their power and independence are being threatened then instinctively they rationalize "lashing out" as acceptable because they are combating oppression and freeing themselves from the confinement of social customs (James et al., 2005).

Taking a closer look at the two facets, both seek to justify aggression as a means to overcome oppression by powerful others (i.e., Victimization by Powerful Others Bias) and by social customs (i.e., Social Discounting Bias). A possible explanation for this relationship is that gender norms have traditionally considered men to be the "dominant" gender so when a man's freedom is oppressed by powerful others or social rules and regulations, men more frequently endorse Victimization by Powerful Others Bias and Social Discounting Bias to justify their aggression. Conversely, women have traditionally been considered the "subordinate" gender group and, as a result, they have either accepted or ceased to notice power differentials. For this reason, women do not frequently endorse Victimization by Powerful Others Bias and Social Discounting Bias 
as JMs for behaving aggressively unlike men. Interestingly, gender differences did not appear for either of the other two predictor measures in this study. However, the literature reveals that correlations between the CRT-A and gender are mixed. In two out of three student samples, "correlations indicated a tendency for young adult, educationallymotivated males to have slightly higher motives to aggress than young adult, educationally-motivated females" (James and McIntyre, 2000, p. 48). Altogether, this suggests that gender differences may exist in how respondents rationalize aggression regardless of how they explicitly report it. Certainly, future research should investigate this relationship of gender differences on the new measure at both the scale level and facet level.

Now, in looking at all of the regression analyses performed for each criterion, alcohol use was the only variable that did not result in a significant $\Delta R^{2}$ after adding the three predictor measures at Step 2 and controlling for the demographics and SDRB in Step 1. A possible explanation for this is because alcohol use is being used as a criterion variable instead of a predictor variable. Intuitively speaking, saying that alcohol use causes aggressive behavior is more logical than saying aggressive behavior causes alcohol use. In fact, the literature confirms a causal relationship with alcohol consumption predicting aggressive behavior (Bushman \& Cooper, 1990; Hull \& Bond, 1986; Ito, Miller, \& Pollock, 1996; Steele \& Southwick, 1985). Also, the literature shows that alcohol consumption increases aggressive behavior for individuals higher on trait aggression (Bailey \& Taylor, 1991; Eckhardt \& Crane, 2008; Giancola, 2002a; Giancola, Godlaski, \& Parrott, 2006; Giancola \& Zeichner, 1995; Moeller, Dougherty, Lane, Steinberg, \& Cherek, 1998). Thus, besides determining convergent validity of the new 
measure via correlational analyses, using this variable as a criterion in MHMR analyses may be one of the limitations of this study.

Lastly, out of fifteen moderated hierarchical multiple regressions, only one interaction effect was found to be significant. This finding was quite surprising considering the advantages stated in the literature about using implicit and explicit cognitions to capture personality and predict behaviors (Bing et al., 2007; Bornstein, 2002; Winter et al., 1998). However, the literature also states that due to low power for detecting interactions, researchers should consider increasing power by setting critical alpha at .10 for the interaction term in MHMR analyses (Cohen, 1988; Champoux \& Peters, 1980; Finn \& Frone, 2004; McClelland \& Judd, 1993). Nonetheless, even after setting critical alpha at .10 there still was no increase in statistically significant interaction terms observed. The only significant interaction term found was between the BPAQ and the new measure in predicting competitiveness. The small amount of incremental variance accounted for by the interaction term $(2.2 \%)$ is substantial considering that the literature reports typical percentages ranging from 1 to 3\% (Champoux \& Peters, 1987; McClelland \& Judd, 1993). As displayed in Figure 1, the positive relationship between the BPAQ scores and competitiveness was stronger for individuals scoring high on the new measure ( 1 standard deviation above the mean). Alternatively, the graph illustrates not much difference in competitiveness for individuals scoring high on the BPAQ but low on the new measure ( 1 standard deviation below the mean). In fact, there seems to be a slight negative relationship between the BPAQ scores and competitiveness when scores on the new measure are low. 
According to a general model integrating explicit cognitions with implicit cognitions (Bing et al., 2007), individuals with high explicit cognitions and implicit cognitions openly claim to be aggressive and have supporting JMs for the behavior as well. Such individuals "pursue goals via direct behaviors easily identifiable as indicative of the motive" (p. 356). Therefore, because of this congruence in explicit and implicit cognitions, these individuals are significantly more competitive. Bing and colleagues (2007) described individuals with high explicit cognitions and low implicit cognitions as those who expend energy convincing themselves and others that they are aggressive but, in fact, they do not have the underlying JMs for aggression. As evidenced by the results of this study, despite claiming to be aggressive and not having supporting JMs for that behavior, these individuals cannot rationalize their behavior as appropriate and are in turn less competitive. Additionally, there seems to be a slight negative relationship between explicit aggression and competitiveness when implicit aggression is low. This can perhaps be attributed to the fact that participants may be influenced by various other factors (e.g., lower self-esteem or self-efficacy) that cause them to devalue their performance, put in less effort, and be less competitive (Bing et al., 2007). An alternate explanation is also provided later in this section.

The question then asked is why is the interaction effect only present for competitiveness and not for any other criterion variable included in this study - violent acts, traffic violations, alcohol use, or agreeableness? One explanation could be that the interaction between implicit and explicit aggression depends on the criterion variable under investigation (Bing et al., 2007). Violent acts, traffic violations, and alcohol use all represent negative behaviors in society and are rarely, if ever, considered prosocial 
because of the stigma associated with them. Essentially, I am proposing that the very nature of the criterion (in this instance, being purely antisocial) may play into the way explicit and implicit aggression interact in its prediction. Due to the restriction of range with alcohol use, I will only focus on violent acts and traffic violations.

For instance, with violent acts, if we were to look at the relationship between the BPAQ and the criterion at high and low levels of the new measure (one standard deviation above and below the mean, respectively) two scenarios could arise. Firstly, the relationship between the BPAQ and violent acts at a high level of the new measure would require a special population that is not being assessed in the present study. Intuitively speaking, individuals who are high on explicit aggression and who have equally high JMs for aggression may represent individuals such as violent offenders (e.g., murderers, rapists, serial killers, psychopaths, and the like). That is, these individuals not only engage in explicit aggression through violent acts but they also readily justify their behaviors as reasonable and even necessary too. Criminological research has found that violent offenders have a high willingness to neutralize offending behavior (Aronson, 1995). According to neutralization theory, the ability for violent offenders to rationalize their behaviors provides "the psychological mechanism through which dissonance [is] reduced and self-concept maintained" (Stevenson, Hall, \& Innes, 2004, p. 170).

Secondly, the relationship between the BPAQ and violent acts at a low level of the new measure would suggest that violent acts may be due in part to impulse and state aggression whereby participants act upon initial feelings of rage but do not actually hold supporting JMs for the behavior. In fact, MHMR analyses revealed that there was a negligible relationship between violent acts and the new measure $(\beta=-.038)$ and a strong 
positive relationship with the BPAQ $(\beta=.293)$, implying that aggression based on JMs (i.e., rationale) may not occur, on average, as respondents engage in violent behaviors. Overall, only one of the two scenarios could have been possible with our sample which potentially explains why no interaction effect was found for violent acts.

With traffic violations, if we were to look at the relationship between the BPAQ and the criterion at high and low levels of the new measure (one standard deviation above and below the mean, respectively) the following two scenarios could arise. Firstly, the relationship between the BPAQ and traffic violations at a high level of the new measure would represent individuals who engage in road rage and justify their aggressive behaviors (e.g., speeding, overtaking and honking at other vehicles, and tailgating) as acceptable. Moderated hierarchical multiple regression results supported this scenario by showing that both explicit $(\beta=.207, p<.01)$ and implicit cognitions $(\beta=.173, p<.05)$ were significant in predicting traffic violations.

Secondly, and less likely, is the relationship between the BPAQ and traffic violations at a low level of the new measure. For violent acts, there is a defensible explanation as to why a person high on explicit aggression at a low level of implicit aggression would commit a violent act (i.e., due to impulse). However, there is less of a logical explanation as to why a person high on explicit aggression at a low level of implicit aggression would commit traffic violations. Driving involves higher-order cognitive processes for gauging distances and speeds, anticipating risky situations, and maneuvering through novel situations and terrain, for example. Thus, it is reasonable to say that these individuals have less occurrences of impulse because they would likely be choosing to act aggressively when driving. Therefore, the very nature of the criterion 
itself allows for greater rationalization of the behavior. Overall, only one of the two scenarios could have been possible with our sample which potentially explains why no interaction effect was found for traffic violations. The details of these scenarios for violent acts and traffic violations are beyond the scope of this study, however, it would be beneficial for future research to investigate these scenarios further. Also, it would be of value to see how the nature of various other criteria play into the way explicit aggression (i.e., BPAQ scores) and implicit aggression (i.e., new measure scores) interact in their prediction.

With agreeableness, unlike the other variables in this study, it is not necessarily a "behavior" predicted by other variables. There are two points to consider in looking at the unique relationship between aggression and the agreeableness construct. Firstly, Costa and McCrae (1992) point out that although people may be inclined to view agreeableness as a positive personality trait; there is no right or wrong way in describing agreeableness. For instance, although agreeable people may be more accepted than antagonistic people, "the readiness to fight for one's own interests is often advantageous, and agreeableness is not a virtue on the battlefield or in the courtroom" (p. 15). In other words, as a stable personality trait, agreeableness is not (and should not be) viewed as good or bad; it simply is a description of a person's interpersonal tendencies. Secondly, the literature shows the buffering effect of agreeableness on aggression, where individuals who are more agreeable are by definition less aggressive because the prosocial nature of agreeableness counteracts the effects of aggressiveness. As a result, an interaction effect between the aggression measures in predicting agreeableness could not have been assessed simply due to the intricate nature of the variable as a dimension of personality, 
neither good nor bad and as an innate defense against aggressive tendencies. Nevertheless, one of the goals of this study was to confirm the negative relationship between aggression and agreeableness as measured by the new scale in particular. Therefore, simply for research design purposes, this is what led to classifying agreeableness as a criterion variable and could be considered as one of the limitations of the study.

As was mentioned previously, competitiveness was the only outcome variable that had a significant interaction effect between the BPAQ and new measure. With competitiveness, this variable can represent both an antisocial behavior as well as a positive, prosocial, one. As an antisocial behavior, it can be viewed as the process of establishing interpersonal dominance over another individual or a group of individuals. As a prosocial behavior, it can be viewed as an individual's drive for achievement and success which is less aggressive in nature. Thus, this prosocial-antisocial dichotomy of competitiveness could have been the basis for why explicit and implicit aggression interacted when predicting competitiveness.

More specifically, the results indicated that the relationship between the BPAQ and competitiveness at a high level of the new measure resulted in greater competitiveness. But, what seem to be driving this high competitiveness are aggressive JMs. Therefore this type of competitiveness represents dominance and ferocity in competition. Yet, the relationship between the BPAQ and competitiveness at a low level of the new measure resulted in minimal change in competitiveness. This type of competitiveness may be representative of a need for achievement and success because the individual is endorsing more prosocial JMs instead of aggressive ones. Certainly more 
research is needed to identify if interaction effects of implicit and explicit cognitions are in fact dependent on the criterion variable of interest. The literature affirms the need to use both implicit and explicit cognitions in personality testing. However, the process of using personality based on explicit and implicit measurement in the prediction of criterion variables still needs further investigation. Studies designed to tackle this issue will better aid researchers and practitioners in understanding the best usage of implicit and explicit measures for predicting a variety of behaviors.

\section{Limitations}

Though several limitations of this study have already been addressed, there are others that should be mentioned. Firstly, the fact that this study was a self-report research design potentially creates a variety of limitations. One such limitation is not allowing for an assessment of causal relationships. However, the goal of this study was not so much to determine causation as it was to investigate general relationships. Also, with selfreporting, issues of common-method bias and social desirability responding arise. Fortunately, both of these issues were considered in the initial design of the study. In an effort to reduce common-method bias, the predictor and criterion measures were collected at two separate times (see Podsakoff, MacKenzie, Lee, \& Podsakoff, 2003). The results revealed that common-method bias was not a pervasive problem because the correlation matrix contained several non-significant relationships within each part of the study, suggesting that common-method bias did not necessarily inflate observed correlations. Additionally, self-reporting allows measures to become more susceptible to faking. But, in anticipation of this, the BIDR (Paulhus, 1984, 1991) measure was used to 
control for any altering of responses in a socially desirable manner. Lastly, all variables were examined for outliers and no extreme values were found that warranted removal As a result of this study being largely exploratory it allowed for a variety of options in running and analyzing the data. In an effort to have a more succinct analysis of data, all three aggression measures were entered at Step 2 of the MHMR analyses. An alternative method would have been to enter each predictor measure separately at Step 2 and take note of each $\Delta R^{2}$. Also, instead of entering all three predictors at Step 2 and then testing each interaction term at Step 3, an alternative could have been to enter just the predictor measure used in the interaction at Step 2 and the corresponding interaction term at Step 3. However, with all of these available options, it should be noted that none of the results changed significantly based on the analysis performed. For instance, with the latter option, due to the fact that the CRT-A was a low and insignificant correlation with each of the criterion variables, it really did not affect the outcomes of the regression analyses when included with the BPAQ and new measure in Step 2.

One other data related issue that may be considered a limitation is the use of pairwise omission versus list-wise omission when handling missing data. Some researchers may argue against pair-wise omission because it results in an ambiguous definition of the sample size causing bias in estimating standard errors and test statistics (Allison, 2001). However, after running the data using both pair-wise and list-wise omission no significant changes were found. For that reason, I decided to report results based on pairwise omission in order to not lose valuable data and to ensure the robustness of the findings (i.e., maintaining a high sample size). 
Lastly, because the CRT-A is a logic-based reasoning test may raise concern to control for general mental ability (GMA) or intelligence. But, according to James and McIntyre (2000) "there is no theoretical reason to expect a correlation between cognitive readiness to aggress and intelligence" (p.47). For example, if intelligence were confounded with responses to conditional reasoning problems then a nonaggressive alternative may in some rational way be "more logical" than aggressive alternatives for intelligent respondents. However, the correlations between the CRT-A and American College Testing (ACT) scores were not significantly correlated for three separate samples (James \& McIntyre, 2000). Additionally, in the present study, cumulative GPA was not significantly correlated with the CRT-A or with the BPAQ and new measure suggesting that no such confounding took place.

\section{Conclusion}

In conclusion, the newly developed measure (Michel, Pace, Edun, Sawhney, \& Thomas, in progress) fills a gap in the literature by operationalizing aggression as reasons for behaving aggressively. It is similar to the BPAQ in the sense that it is a self-report; however, the moderate correlation between the two suggests that each is measuring slightly different aspects of aggression. It was expected that the new measure would have correlated higher with the CRT-A but the results revealed otherwise. Thus, further research needs to explore exactly what JMs or reasoning for aggressive behavior are being tapped into by the new measure. Although not hypothesized, this study proposes that the relationship between implicit and explicit cognitions in the prediction of criterion variables is dependent on the nature of the criterion itself. For instance, if a criterion variable, such as competitiveness, can qualify as both antisocial and prosocial then an 
interaction effect between the predictors is more likely. However, if the criterion variable is solely antisocial in nature, such as violent acts and traffic violations, then only main effects would be present depending on the sample being used. Additionally, the manner in which criterion variables are operationalized (e.g., overt aggressiveness versus covert aggressiveness) likely influences the predictive validity of implicit and explicit predictors on the criteria. Thus, future studies should use these findings to add to the validity and generalizability of the new measure and further explore the main and interaction effects in predicting other criteria. 


\section{REFERENCES}

Aiken, L. S., \& West, S. G. (1991). Multiple regression: Testing and interpreting interactions. Newbury Park, CA: Sage.

Ajzen, I., \& Fishbein, M. (2005). The influence of attitudes on behavior. In D. Albarracín, B. T. Johnson, \& M. P. Zanna (Eds.), The handbook of attitudes (pp. 173-221). Mahwah, NJ: Erlbaum.

Allison, P. D., (2001) Missing Data. Sage University Papers Series on Quantitative Applications in the Social Sciences, 07-136. Thousand Oaks, CA: Sage.

Anderson, C. A., \& Bushman, B. J. (2001). Effects of violent video games on aggressive behavior, aggressive cognition, aggressive affect, physiological arousal, and prosocial behavior: A meta-analytic review of the scientific literature. Psychological Science, 12, 353-359.

Anderson, C. A., \& Bushman, B. J. (2002). Human aggression. Annual Review of Psychology, 53, 27-51.

Anderson, C. A., Gentile, D. A., \& Buckley, K. E. (2007). Violent video game effects on children and adolescents: Theory, research, and public policy. New York, NY: Oxford University Press.

Archer, J. (1992). Ethology and Human Development, Hemel Hempsted, UK: HarvesterWheatsheaf.

Archer, J. (2004). Sex differences in aggression in real-world settings: A meta-analytic review. Review of General Psychology, 8, 291-322.

Archer, J., \& Webb, I. (2006). The relation between scores on the Buss-Perry Aggression Questionnaire and aggressive acts, impulsiveness, competitiveness, dominance, and sexual jealousy. Aggressive Behavior, 32, 464-473.

Arnett, J. J., Offer, D., \& Fine, M. A. (1997). Reckless driving in adolescence: 'State' and 'trait' factors. Accident Analysis and Prevention, 29, 57-63.

Aronson, E. A. (1995). The social animal (7th ed.). New York: Freeman.

Atkinson, J.W (1957). Motivational determinants of risk-taking behavior. Psychological Review, 64, 359-372.

Atkinson, J. W (1964). An introduction to motivation. New York: Van Nostrand Rienhold. 
Atkinson, J. W. (1978). The mainsprings of achievement-oriented activity. In J. W. Atkinson \& J. O. Raynor (Eds.), Personality, motivation, and achievement (pp. 11-39). Washington, DC: Hemisphere.

Bailey, D. S., \& Taylor, S. P. (1991). Effects of alcohol and aggressive disposition on human physical aggression. Journal of Research in Personality, 25, 334-342.

Bandura, A. (1973). Aggression: A social learning theory analysis. Englewood Cliffs, NJ: Prentice Hall.

Barbour, K. A., Eckhardt C. I., Davison, G. C., \& Kassinove, H. (1998). The experience and expression of anger in maritally violent and maritally discordant-nonviolent men. Behavior Therapy, 29, 173-191.

Baron, R. A., \& Richardson, D. R. (1994). Human aggression (2nd Edition). New York, NY: Plenum Press.

Barratt, E. S., \& Slaughter, L. (1998). Defining, measuring, and predicting impulsive aggression: A heuristic model. Behavioral Sciences and the Law, 16, 285-302.

Baumeister, R. F., Smart, L., \& Boden, J. M. (1996). Relation of threatened egotism to violence and aggression: The dark side of high self-esteem. Psychological Review, 103, 5-33.

Bennett, L., \& Lawson, M. (1994). Barriers to cooperation between domestic violence and substance abuse programs. Families in Society: The Journal of Contemporary Human Services, 75, 277-286.

Bergen, H. A., Martin, G., Richardson, A. S., Allison, S., \& Roeger, L. (2004). Sexual abuse, antisocial behaviour and substance use: Gender differences in young community adolescents. Australian and New Zealand Journal of Psychiatry, 38, $34-41$.

Berkowitz, L. (1983). The experience of anger as a parallel process in the display of impulsive, "angry" aggression. In R. G. Geen \& E. I. Donnerstein (Eds.), Aggression: Theoretical and empirical reviews (Vol. 1, pp. 103-134). New York: Academic Press.

Berkowitz, L. (1989). Laboratory experiments in the study of aggression. In J. Archer \& K. Browne (Eds.), Human aggression: Naturalistic approaches (pp. 42-61). New York: Routledge.

Berkowitz, L. (1993). Aggression: Its causes, consequences, and control. New York: McGraw Hill. 
Bettencourt, B. A., Talley, A., Benjamin, A. J., \& Valentine, J. (2006). Personality and aggressive behavior underprovoking and neutral conditions: A meta-analytic review. Psychological Bulletin, 132, 751-777.

Bies, R. J., \& Tripp, T. M. (1998). The many faces of revenge: The good, the bad, and the ugly. In R. W. Griffin, A. M. O’Leary-Kelly, \& J. Collins (Eds.), Dysfunctional behavior in organizations (pp. 49-68). Greenwich, CT: JAI Press.

Bing, M. N., LeBreton, J. M., Davison, H. K., Migetz, D. Z., \& James, L. R. (2007). Integrating implicit and explicit social cognitions for enhanced personality assessment: A general framework for choosing measurement and statistical methods. Organizational Research Methods, 10, 136-179.

Bing, M. N., Stewart, S. M., Davison, H. K., Green, P. D., McIntyre, M. D., \& James, L. R. (2007). An integrative typology of personality assessment for aggression: Implications for predicting counterproductive workplace behavior. Journal of Applied Psychology, 92, 722-744.

Bornstein, R. F. (2002). A process dissociation approach to objective-projective test score interrelationships. Journal of Personality Assessment, 78, 47-68.

Brewin, C. R. (1989). Cognitive change processes in psychotherapy. Psychological Review, 96, 379-394.

Brown, S. A., Goldman, M. S., Inn, A., \& Anderson, L. R. (1980). Expectancies of reinforcement from alcohol: Their domain and relation to drinking patterns. Journal of Consulting and Clinical Psychology, 48, 419-426.

Burman, B., Margolin, G., \& John, R. S. (1993). America's angriest home videos: Behavioral contingencies observed in home reenactments of marital conflict. Journal of Consulting and Clinical Psychology, 61, 28-39.

Bushman, B. J., \& Anderson, C. A. (2001). Media violence and the American public: Scientific facts versus media misinformation. American Psychologist, 56, 477489.

Bushman, B. J., \& Cooper, H. M. (1990). Effects of alcohol on human aggression: An integrative research review. Psychological Bulletin, 107, 341-354.

Buss, A. (1961). The psychology of aggression. New York: John Wiley.

Buss, A. H., \& Durkee, A. (1957). An inventory for assessing different kinds of hostility. Journal of Consulting Psychology, 21, 343-349. 
Buss, A. H., \& Perry, M. (1992). The aggression questionnaire. Journal of Personality and Social Psychology, 63, 452-459.

Cairns R. B., \& Cairns B.D. (1994). Lifelines and risks: Pathways of youth in our time. Cambridge: University Cambridge Press.

Campbell A. (1995). A few good men: Evolutionary psychology and female adolescent aggression. Ethology and Sociobiology, 16, 99-123.

Campbell, A. (1999). Staying alive: Evolution, culture, and women's intrasexual aggression. Behavioral and Brain Sciences, 22, 203-214.

Campbell, D. \& Fiske, D. (1959). Convergent and discriminant validation by the multitrait-multimethod matrix. Psychological Bulletin, 56, 81-105.

Caprara, G. V., Barbaranelli, C., \& Zimbardo, P. G. (1996). Understanding the complexity of human aggression: Affective, cognitive, and social dimensions of individual differences in propensity toward aggression. European Journal of Personality, 10, 133-155.

Champoux, J. E., \& Peters, W. S. (1980). Applications of moderated regression in job design research. Personnel Psychology, 33, 759-783.

Champoux, J. E., \& Peters,W. S. (1987). Form, effect size, and power in moderated regression analysis. Journal of Occupational Psychology, 60, 243-255.

Chermack, S. T., \& Giancola, P. R. (1997). The relation between alcohol and aggression: An integrated biopsychosocial conceptualization. Clinical Psychology Review, 17, 621-649.

Chermack, S. T., \& Taylor, S. P. (1995). Alcohol and human physical aggression: Pharmacological versus expectancy effects. Journal of Studies on Alcohol, 56, 449-456.

Cohen, J. (1988). Statistical power analysis for the behavioral sciences (2nd ed.). Hillsdale, NJ: Lawrence Erlbaum.

Cohen, J., \& Cohen, P. (1983). Applied multiple regression/correlation analysis for the behavioral sciences (2nd edition). Hillsdale, NJ: Erlbaum.

Coie, J. D., \& Dodge, K. A. (1998). Aggression and antisocial behavior. In N. Eisenberg (Ed.), Handbook of Child Psychology (pp. 779-862). New York: Wiley. 
Collins, J. J., Schlenger, W. E., \& Jordan, B. K. (1988). Antisocial personality and substance abuse disorders. Bulletin of the American Academy of Psychiatry \& the Law, 16, 187-198.

Costa, P. T., \& McCrae, R. R. (1992). Revised NEO -Personality Inventory (NEO-PI-R) and NEO Five-Factor Inventory (FFI) manual. Odessa, FL: Psychological Assessment Resources.

Crawford, A. (1984a). Alcohol and expectancy - I. Perceived sex differences in the effects of drinking. Alcohol \& Alcoholism, 19, 63-69.

Crawford, A. (1984b). Alcohol and expectancy - II. Perceived sex differences in the role of alcohol as a source of aggression. Alcohol \& Alcoholism, 19, 71-75.

Crick, N. R.,\& Dodge, K. A. (1994). A review and reformulation of social information processing mechanisms in children's adjustment. Psychological Bulletin, 115, 74101.

Crooks, C. V., Scott, K. L., Wolfe, D. A., Chiodo, D., \& Killip, S. (2007). Understanding the link between childhood maltreatment and violent delinquency: What do schools have to add? Child Maltreatment, 12, 269-280.

Daly, M., \& Wilson, M. (1994).Evolutionary psychology of maleviolence. In J. Archer (Ed.), Male violence (pp. 253-288). London: Routledge.

Deffenbacher, J. L., Huff, M. E., Lynch, R. S., Oetting, E. R., \& Salvatore, N. F. (2000).Characteristics and treatment of high-anger drivers. Journal of Counseling Psychology, 47, 5-17.

Deffenbacher, J. L., Lynch, R. S., Oetting, E. R., \& Yingling, D. A. (2001). Driving anger: Correlates and a test of state-trait theory. Personality and Individual Differences, 31, 1321-1331.

Deffenbacher, J. L., Oetting, E. R., \& Lynch, R. S. (1994). Development of a driving anger scale. Psychological Reports, 74, 83-91.

DePasquale, J. P., Geller, E. S., Clarke, S. W., \& Littleton, L. C. (2001).Measuring road rage: Development of the Propensity for Angry Driving Scale. Journal of Safety Research, 32, 1-16.

Dodge, K. A., \&Coie, J. D. (1987). Social-information-processing factors in reactive and proactive aggression in children's peer groups. Journal of Personality and Social Psychology, 53, 1146-1158. 
Dodge, K. A., Lochman, J. E., Harnish, J. D., Bates, J. E., \& Petit, G. S. (1997). Reactive and proactive aggression in school children and psychiatrically impaired chronically assaultive youth. Journal of Abnormal Psychology, 106, 37-51.

Dollard, J., Doob, L. W., Miller, N. E., Mowrer, O. H., \& Sears, R. R. (1939). Frustration and aggression. New Haven, CT: Yale University Press.

Eckhardt, C. I., \& Crane, C. (2008). Effects of alcohol intoxication and aggressivity on aggressive verbalizations during anger arousal. Aggressive Behavior, 34, 428436.

Eckhardt, C. I., Norlander, B., \& Deffenbacher, J. (2004). The assessment of anger and hostility: A critical review. Aggression and Violent Behavior, 9, 17-43.

Edwards, A. L. (1957). The social desirability variable in personality assessment and research. New York: Holt, Rinehart and Winston.

Edwards, J. B. (1999). Speed adjustment of motorway commuter traffic to inclement weather. Transportation Research Part F: Traffic Psychology and Behaviour, 2, $1-14$.

Ellison-Potter, P. A., Govern, J. M., Petri, H. L., \& Figler, M. H. (1995). Anonymity and aggressive driving behavior: A field study. Journal of Social Behavior and Personality, 10, 265-272.

Epstein, S. (1994). Integration of the cognitive and the psychodynamic unconscious. American Psychologist, 49, 709-724.

Fals-Stewart, W. (2003). The occurrence of partner physical aggression on days of alcohol consumption: A longitudinal diary study. Journal of Consulting and Clinical Psychology, 71, 41-52.

Fazio, R. H., \& Olson, M. A. (2003). Implicit measures in social cognition research. Annual Review of Psychology, 54, 297-327.

Felson, R. B., \& Tedeschi, J. T. (Eds.). (1993). Aggression and violence: Social interactionist perspectives. Washington, DC: American Psychological Association.

Feshbach, N. (1964). The function of aggression and the regulation of aggressive drive. Psychological Review, 71, 257-272.

Field, C. A., Caetano, C., \& Nelson, S. (2004). Alcohol and violence related cognitive risk factors associated with the perpetration of intimate partner violence. Journal of Family Violence, 19, 249-253. 
Finn, K. V., \& Frone, M. R. (2004). Academic performance and cheating: Moderating role of school identification and self-efficacy. Journal of Educational Research, 97, 115-122.

Friedman, M., \& Rosenman, R. (1974). Type A behavior and your heart. Knopf, New York.

Fox, S., \& Spector, P. E. (1999). A model of work frustration-aggression. Journal of Organizational Behavior, 20, 915-932.

Gantner, A. B., \& Taylor, S. P. (1992). Human physical aggression as a function of alcohol and threat of harm. Aggressive Behavior, 18, 29-36.

Galovski, T. E., \& Blanchard, E. B. (2002). The effectiveness of a brief psychological intervention on court-referred and self-referred aggressive drivers. Behaviour Research and Therapy, 40, 1385-1402.

Geen, R. (2001). Human aggression (2nd Edition). Buckingham: Open University Press.

Giancola, P. R. (2002a). Alcohol-related aggression in men and women: The influence of dispositional aggressivity. Journal of Studies on Alcohol, 63, 696-708.

Giancola, P. R. (2002b). Irritability, acute alcohol consumption and aggressive behavior in men and women. Drug and Alcohol Dependence, 68, 263-274.

Giancola, P. R. (2003). The moderating effects of dispositional empathy on alcoholrelated aggression in men and women. Journal of Abnormal Psychology, 112, 275-281.

Giancola, P. R. (2004). Executive functioning and alcohol-related aggression. Journal of Abnormal Psychology, 113, 541-555.

Giancola, P. R., Godlaski, A. J., \& Parrott, D. J. (2006). "So I can't blame the booze?" Dispositional aggressivity negates the moderating effects of expectancies on alcohol-related aggression. Journal of Studies on Alcohol, 66, 815-824.

Giancola, P. R., Helton, E. L., Osborne, A. B., Terry, M. K., Fuss, A. M., \& Westerfield, J. A. (2002). The effects of alcohol and provocation on aggressive behavior in men and women. Journal of Studies on Alcohol, 63, 64-73.

Giancola, P. R., \&Zeichner, A. (1995). Alcohol-related aggression in males and females: Effects of blood alcohol concentration, subjective intoxication, personality, and provocation. Alcoholism: Clinical and Experimental Research, 19, 130-134. 
Giancola, P. R., \& Zeichner, A. (1997). The biphasic effects of alcohol on human physical aggression. Journal of Abnormal Psychology, 106, 598-607.

Gleason, K. A., Jensen-Campbell, L. A., \& Richardson, D. S. (2004). Agreeableness as a predictor of aggression in adolescence. Aggressive Behavior, 30, 43-61.

Goldberg, L. R. (1999). A broad-bandwidth, public domain, personality inventory measuring the lower-level facets of several five-factor models. In I. Mervielde, I. Deary, F. De Fruyt, \& F. Ostendorf (Eds.), Personality Psychology in Europe, Vol. 7 (pp. 7-28). Tilburg, The Netherlands: Tilburg University Press.

Graham, K., Wells, S., \& West, P. (1997).A framework for applying explanations of alcohol-related aggression to naturally occurring aggressive behavior. Contemporary Drug Problems, 24, 625-666.

Graziano, W. G., \& Eisenberg, N. (1997). Agreeableness: A dimension of personality. In R. Hogan, J. Johnson, \& S. Briggs (Eds.), Handbook of personality psychology (pp. 795-824). San Diego, CA: Academic Press.

Greenwald, A. G., \& Banaji, M. R. (1995). Implicit social cognition: Attitudes, selfesteem, and stereotypes. Psychological Review, 102, 4-27.

Gustafson, R. (1985). Alcohol and aggression: Pharmacological versus expectancy effects. Psychological Reports, 57, 955-966.

Gustafson, R. (1992). Alcohol and aggression: A replication study controlling for potential confounding variables. Aggressive Behavior, 18, 21-28.

Harris, P. B., \& Houston, J. M. (2010). Recklessness in context: Individual and situational correlates to aggressive driving. Environment and Behavior, 42, 44-60.

Hensley, C., \& Tallichet, S. E. (2009). Childhood and adolescent animal cruelty methods and their possible link to adult violent crimes. Journal of Interpersonal Violence, $24,147-158$.

Hogan, R. (1991). Personality and personality measurement. In M. D. Dunnette \& L. M. Hough (Eds.), Handbook of industrial and organizational psychology (Vol. 2, pp. 873-919). Palo Alto, CA: Consulting Psychologists Press.

Holmes, D. S. (1974). The conscious control of thematic projection. Journal of Consulting and Clinical Psychology, 42, 323-329.

Houston, J. M., Harris, P. B., Norman, M. (2003). The Aggressive Driving Behavior Scale: Developing a self-report measure of unsafe driving practices. North American Journal of Psychology, 5, 269-278. 
Huesmann, L. R. (1988). An information processing model for the development of aggression. Aggressive Behavior, 14, 13-24.

Hull, J. G., \& Bond, C. F. (1986). Social and behavioral consequences of alcohol consumption and expectancy: A meta-analysis. Psychological Bulletin, 99, 347360 .

Ito, T. A., Miller, N., \& Pollock, V. E. (1996). Alcohol and aggression: A meta-analysis on the moderating effects of inhibitory cues, triggering events, and self-focused attention. Psychological Bulletin, 120, 60-82.

Jackman, M. (2002). Violence in social life. Annual Review of Sociology, 28, 387-415.

James, L. R. (1998). Measurement of personality via conditional reasoning. Organizational Research Methods, 1, 131-163.

James, L. R., \& Mazerolle, M. D. (2002).Personality in work organizations. Thousand Oaks, CA: Sage.

James, L. R., \& Mclntyre, M. D. (2000). Conditional Reasoning Test of Aggression test manual. Knoxville, TN: Innovative Assessment Technology.

James, L. R., McIntyre, M. D., Glisson, C. A., Bowler, J. L., \& Mitchell, T. R. (2004). The conditional reasoning measurement system for aggression: An overview. Human Performance, 17, 271-295.

James, L. R., McIntyre, M. D., Glisson, C. A., Green, P. D., Patton, T. W., LeBreton, J. M., et al. (2005). Conditional reasoning: An efficient, indirect method for assessing implicit cognitive readiness to aggress. Organizational Research Methods, 8, 69-99.

Kelly, T. H., \& Cherek, D. R. (1993). The effects of alcohol on free-operant aggressive behavior. Journal of Studies on Alcohol, 11, 40-52.

Lange A., Pahlich A., Sarucco M., Smits G., Dehghani B. \& Hanewald G. (1995). Psychometric characteristics and validity of the Dutch adaptation of the BussDurkee Hostility Inventory (the BDHI-D). Behaviour Research and Therapy 33, $223-227$.

Laplace, A. C., Chermack, S. T., \& Taylor, S. P. (1994). Effects of alcohol and drinking experience on human physical aggression. Personality and Social Psychology Bulletin, 20, 439-444. 
LeBreton, J. M., Barksdale, C. D., Robin, J., \& James, L. R. (2007). Measurement issues associated with conditional reasoning tests: Indirect measurement and test faking. Journal of Applied Psychology, 92, 1-16.

LeBreton, J. M., Binning, J. F., \& Adorno, A. J. (2006). "Sub-clinical” psychopaths. In J. C. Thomas \& D. Segal (Eds.), Comprehensive handbook of personality and psychopathology (Vol. 1, Personality and everyday functioning, pp. 388-411). New York: John Wiley and Sons.

Loeber, R., \& Hay, D. (1997). Key issues in the development of aggression and violence from childhood to early adulthood. Annual Review of Psychology, 48, 371-410.

Lynch, R.S., Deffenbacher, J.L., Filetti, L.B., \& Dahlen, E.R. (August, 1999). Characteristics and treatment of individuals with high and low driving anger. Paper presented at the $107^{\text {th }}$ annual convention of the American Psychological Association, Boston, MA.

McClelland, D. C. (1985). Human motivation. Glenview, IL: Scott, Foresman.

McClelland, D. C., Koestner, R., \& Weinberger, J. (1989). How do self-attributed and implicit motives differ? Psychological Review, 96, 690-702.

McClelland, G. H., \& Judd, C. M. (1993). Statistical difficulties of detecting interactions and moderator effects. Psychological Bulletin, 114, 376-390.

Martin, R., Watson, D., \& Wan, C. K. (2000). A three-factor model of trait anger: Dimensions of affect, behavior, and cognition. Journal of Personality, 68, 869897.

Mead, M. (1964). Cultural factors in the cause and prevention of pathological homicide. Bull Menninger Clinic, 28, 11-22.

Meier, B. P., \& Robinson, M. D. (2004). Does quick to blame mean quick to anger? The role of agreeableness in dissociating blame and anger. Personality and Social Psychology Bulletin, 30, 856-867.

Meier, B. P., Robinson, M. D., \& Wilkowski, B. M. (2006).Turning the other cheek: Agreeableness and the regulation of aggression-related primes. Psychological Science, 17, 136-142.

Meier, B. P., Wilkowski, B. M., \& Robinson, M. D. (2008).Bringing out the agreeableness in everyone: Using a cognitive self-regulation model to reduce aggression. Journal of Experimental Social Psychology, 44, 1383-1387. 
Merz-Perez, L., \& Heide, K. M. (2003). Animal cruelty: Pathway to violence against people. Lanham, MD: Rowman\& Littlefield.

Merz-Perez, L., Heide, K. M., \& Silverman, I. J. (2001). Childhood cruelty to animals and subsequent violence against humans. International Journal of Offender Therapy and Comparative Criminology, 45, 556-573.

Michel, J., Pace, V., Edun, A., Sawhney, E., \& Thomas, J. (In progress). Development and validation of a self-report aggression measure.

Mischel, W., \& Shoda, Y. (1995). A cognitive-affective system theory of personality: Reconceptualizing situations, dispositions, dynamics, and invariance in personality structure. Psychological Review, 102, 246-268.

Moeller, F. G., Dougherty, D. M., Lane, S. D., Steinberg, J. L., \& Cherek, D. R. (1998). Antisocial personality disorder and alcohol-induced aggression. Alcoholism: Clinical and Experimental Research, 22, 1898-1902.

Murphy, C. M., \& O’Leary, K. D. (1989). Psychological aggression predicts physical aggression in early marriage. Journal of Consulting and Clinical Psychology, 57, 579-582.

Nagin, D. S., \& Tremblay, R. E. (1999). Trajectories of boys’ physical aggression, opposition, and hyperactivity on the path to physically violent and nonviolent juvenile delinquency. Child Development, 70, 1181-1196.

National Highway Traffic Safety Administration. (2010). Traffic safety facts: An early estimate of motor vehicle traffic fatalities in 2009 (NHTSA Report DOT HS 811 291). Washington DC: National Center for Statistics and Analysis, U.S. Department of Transportation. Retrieved May 1, 2010, from http://wwwnrd.nhtsa.dot.gov/Pubs/811291.pdf

Neuman, J. H., \& Baron, R. A. (1998). Workplace violence and workplace aggression: evidence concerning specific forms, potential causes, and preferred targets. Journal of Management, 24, 391-419.

Nisbett, R. E., \& Wilson, T. D. (1977). Telling more than we can know: Verbal reports on mental processes. Psychological Review, 84, 231-259.

Nomellini, S., \& Katz, R. C. (1983). Effects of anger control training in abusive parents. Cognitive Therapy and Research, 7, 57-68.

Norris, F. H., Matthews, B. A., \& Riad, J. K. (2000).Characterological, situational, and behavioral risk factors for motor vehicle accidents: A prospective examination. Accident Analysis and Prevention, 32, 505-515. 
Novaco, R. W., Kliewer, W., \& Broquet, A. (1991). Home environmental consequences of commute travel impedance. American Journal of Community Psychology, 19, 881-909.

Novaco, R. W., Stokols, D., Campbell, J., \& Stokols, J. (1979).Transportation, stress, and community psychology. American Journal of Community Psychology, 7, 361-380.

Novaco, R. W., Stokols, D., \& Milanesi, L. (1990).Objective and subjective dimensions of travel impedance as determinants of commuting stress. American Journal of Community Psychology, 18, 231-257.

Nunnally, J. C., \& Bernstein, I. H. (1994). Psychometric theory (3 ${ }^{\text {rd }}$ Ed.). New York: McGraw-Hill.

Orpen, C. (1978). Conscious control of projection in the thematic apperception test. Psychology: A Journal of Human Behavior, 15, 67-75.

Parrott, D. J., \& Giancola, P. R. (2004). A further examination of the relation between trait anger and alcohol-related aggression: The role of anger control. Alcoholism: Clinical and Experimental Research, 28, 855-864.

Parrott, D. J., \& Giancola, P. R. (2007). Addressing "the criterion problem" in the assessment of aggressive behavior: Development of a new taxonomic system. Aggression and Violent Behavior: A Review Journal, 12, 280-299.

Parrott, D. J., \& Zeichner, A. (2002). Effects of alcohol and trait anger on physical aggression in men. Journal of Studies on Alcohol, 63, 196-204.

Paulhus, D. L. (1984). Two-component model of socially desirable responding. Journal of Personality and Social Psychology, 46, 598-609.

Paulhus, D. L. (1991). Measurement and control of response bias. In J. P. Robinson, P. R. Shaver, \& L. S. Wrightsman (Eds.), Measures of personality and social psychological attitudes (pp. 17-59). San Diego, CA: Academic Press.

Paulhus, D. L. (2002). Socially desirable responding: The evolution of a construct. In H. Braun, D. N. Jackson, \&D.E. Wiley (Eds.), The role of constructs in psychological and educational measurement (pp.67-88). Hillsdale, NJ: Erlbaum.

Pernanen, K. (1991). Alcohol in human violence. New York, NY: Guilford Press.

Pihl, R. O., Peterson, J. B., \& Lau, M. A. (1993). A biosocial model of the alcoholaggression relationship. Journal of Studies on Alcohol, 11, 128-139.

Pihl, R. O., \& Zacchia, C. (1986). Alcohol and aggression: A test of the affect-arousal hypothesis. Aggressive Behavior, 12, 367-375. 
Podsakoff, P. M., MacKenzie, S. B., Lee, J. Y., \& Podsakoff, N. P. (2003). Common method biases in behavioral research: A critical review of the literature and recommended remedies. Journal of Applied Psychology, 88, 879-903.

Polman, H., Orobio de Castro, B., \& Van Aken, M. A. G. (2008). Experimental study of the differential effects of playing versus watching violent video games on children's aggressive behavior. Aggressive Behavior, 34, 256-264.

Purdy, F., \& Nickle, N. (1981). Practice principles for working with groups of men who batter. Social Work with Groups, 4, 111-122.

Ramírez, J. M., \& Andreu, J. M. (2006). Aggression, and some related psychological constructs (anger, hostility, and impulsivity) some comments from a research project. Neuroscience and Biobehavioral Reviews, 30, 276-291.

Reiss, A. J., \& Roth, J. A., (1993). Alcohol, other psychoactive drugs and violence. In: A. J. Reiss and J. A. Roth (Eds.), Understanding and preventing violence (pp. 182220). Washington, DC: National Academy Press.

Roizen, J. (1993). Issues in the epidemiology of alcohol and violence. In S. E. Martin (Ed.), Alcohol and interpersonal violence: Fostering multidisciplinary perspectives (pp. 3-36). Bethesda, MD: National Institute on Alcohol Abuse and Alcoholism.

Rosenman, R. H. (1978). The interview method of assessment of the Type A coronaryprone behavior pattern. In Dembroski, T. M., Weiss, S. M., Shields, J. L., Haynes, S. G., and Feinleib, M. (Eds.), Coronary-Prone Behavior. Springer-Verlag, New York.

Ruiz, J. M., Smith, T. W., \& Rhodewalt, F. (2001).Distinguishing narcissism and hostility: Similarities and differences in interpersonal circumplex and five-factor correlates. Journal of Personality Assessment, 76, 537-555.

Rutter, M., Giller, H., \& Hagell, A. (1998). Antisocial behavior by young people. Cambridge, UK: Cambridge University Press.

Sacket, P. R., \& Larson, J. R. (1990). Research strategies and tactics in industrial and organizational psychology. In M. D. Dunnette \& L. M. Hough (Eds.), Handbook of industrial and organizational psychology (pp. 419-489). Palo Alto, CA: Consulting Psychologists Press.

Schwarz, N. (1999). Self-reports: How the questions shape the answers. American Psychologist, 54, 93-105. 
Sharpe, J. P., \& Desai, S. (2001). The revised NEO Personality Inventory and the MMPI2 Psychopathology Five in the prediction of aggression. Personality and Individual Differences, 31, 505-518.

Shinar, D., \& Compton, R. (2004). Aggressive driving: An observational study of driver, vehicle, and situational variables. Accident Analysis \& Prevention, 36, 429-437.

Shuntich, R. J., \& Taylor, S. P. (1972).The effects of alcohol on human physical aggression. Journal of Experimental Research in Personality, 6, 34-38.

Simmons, C. H., Wehner, E. A., Tucker, S. S., \& King, C. S. (1988). The Cooperative/Competitive Strategy Scale: A measure of motivation to use cooperative or competitive strategies for success. The Journal of Social Psychology, 128, 199-205.

Smith, C., \& Thornberry, T. P. (1995).The relationship between childhood maltreatment and adolescent involvement in delinquency. Criminology, 33, 451-481.

Smither, R. D., \& Houston, J. M. (1992). The nature of competitiveness: The development and validation of the Competitiveness Index. Educational and Psychological Measurement, 52, 407-418.

Smits, D. J. M., \& De Boeck, P. (2007). From anger to verbal aggression: Inhibition at different levels. Personality and Individual Differences, 43, 47-57.

Snyder, H. N., \& Sickmund, M. (1999). Juvenile offenders and victims: 1999 national report. Pittsburgh, PA: National Center for Juvenile Justice, U.S. Department of Justice.

Sonkin, D. J., Martin, D., \& Walker, L. (1985). The mule batterer: A treatment approach. New York: Springer.

Spangler,W. D. (1992). Validity of questionnaire and TAT measures of need for achievement: Two meta-analyses. Psychological Bulletin, 112, 140-154.

Spence, J. T., \& Helmreich, R. L. (1983). Achievement-related motives and behavior. In J. T. Spence (Ed.), Achievement and achievement motives: Psychological and sociological approaches (pp. 7-74). San Francisco: Freeman

Spielberger, C. D. (1988). Manual for the State-Trait Anger Expression Inventory. Odessa, FL: Psychological Assessment Resources.

Spielberger, C. D., Jacobs, G., Russell, S., \& Crane, R. (1983). Assessment of anger: The State-Trait Anger Scale. In J. N. Butcher \& C.D. Spielberger (Eds.), Advances in personality assessment, Vol. 2 (pp. 159-187). Hillsdale, NJ: Erlbaum. 
Steele, C. M., \& Josephs, R. A. (1990). Alcohol myopia: Its prized and dangerous effects. American Psychologist, 45, 921-933.

Steele, C. M., \& Southwick, L. (1985). Alcohol and social behavior: I. The psychology of drunken excess. Journal of Personality and Social Psychology, 48, 18-34.

Stevenson, S. F., Hall, G., \& Innes, J. M. (2004). Rationalizing criminal behaviour: The influence of criminal sentiments on sociomoral development in violent offenders and nonoffenders. International Journal of Offender Therapy and Comparative Criminology, 48, 161-174.

Straus, M. A. (1979). Measuring intrafamily conflict and violence: The Conflict Tactics (CT) Scales. Journal of Marriage and the Family, 41, 75-86.

Swanston, H. Y., Parkinson, P. N., O'Toole, B. I., Plunkett, A. M., Shrimpton, S., \& Oates, R. K. (2003). Juvenile crime, aggression and delinquency after sexual abuse: A longitudinal study. British Journal of Criminology, 43, 729-749.

Tallichet, S. E., \& Hensley, C. (2004).Exploring the link between recurrent acts of childhood and adolescent animal cruelty and subsequent violent crime. Criminal Justice Review, 29, 304-316.

Taylor, S. P., \& Chermack, S. T. (1993).Alcohol, drugs and human physical aggression. Journal of Studies on Alcohol, 11, 78-88.

Taylor, S. P., \& Gammon, C. B. (1975). Effects of type and dose of alcohol on human physical aggression. Journal of Personality and Social Psychology, 32, 169-175.

Taylor S. P., \& Gammon, C. B. (1976). Aggressive behavior of intoxicated subjects: The effect of third-party intervention. Journal of Studies on Alcohol, 32, 169-175.

Taylor, S. P., Gammon, C. B., \& Capasso, D. R. (1976).Aggression as a function of the interaction of alcohol and threat. Journal of Personality and Social Psychology, 34, 938-941.

Taylor, S. P., Schmutte, G., Leonard, K., \& Cranston, J. (1979).The effects of alcohol and extreme provocation on the use of a highly noxious electric shock. Motivation and Emotion, 3, 73-81.

Taylor, S. P., \& Sears, J. D. (1988).The effects of alcohol and persuasive social pressure on human physical aggression. Aggressive Behavior, 14, 237-243.

Toch, H. (1993). Good violence and bad violence: Self-presentations of aggression through accounts and war stories. In R. B. Felson \& J. T. Tedeschi (Eds.), 
Aggression and violence: Social interactionist perspectives (pp. 193-206).

Washington, DC: American Psychological Association.

Toscano, G., \& Weber, W. (1995).Violence in the workplace. Washington, DC: U.S. Department of Labor Statistics.

Tremblay, P. F., Graham, K., \& Wells, S. (2008). Severity of physical aggression reported by university students: A test of the interaction between trait aggression and alcohol consumption. Personality and Individual Differences, 45, 3-9.

Walker, L. (1979). The battered woman. New York: Harper \& Row.

Watson, D., \& Clark, L. A. (1992b). On traits and temperament: General and specific factors of emotional experience and their relation to the five-factor model. Journal of Personality, 60, 441-476.

Westen, D. (1998). The scientific legacy of Sigmund Freud: Toward a psychodynamically informed psychological science. Psychological Bulletin, 124, 333-371.

Winter, D. G., John, O. P., Stewart, A. J., Klohnen, E. C., \& Duncan, L. E. (1998). Traits and motives: Toward an integration of two traditions in personality research. Psychological Review, 105, 230-250.

Wright, J. C., \& Mischel, W. (1987). A conditional approach to dispositional constructs: The local predictability of social behavior. Journal of Personality and Social Psychology, 55, 454-469.

Zeichner, A., Allen, J. D., Giancola, P. R., \& Lating, J. (1994). Alcohol and aggression: Effects of personal threat on human aggression and affective arousal. Alcoholism: Clinical and Experimental Research, 18, 657-663.

Zeichner, A., Giancola, P. R., \& Allen, J. D. (1995). Effects of hostility on alcohol stress response-dampening. Alcoholism: Clinical and Experimental Research, 19, 977983.

Zeichner, A., \& Pihl, R. O. (1979).Effects of alcohol and behavior contingencies on human aggression. Journal of Abnormal Psychology, 88, 153-160.

Zeichner, A., \& Pihl, R. O. (1980).The effects of alcohol and instigator intent on human aggression. Journal of Studies on Alcohol, 41, 265-276.

Zeichner, A., Pihl, R. O., Niaura, R., \& Zacchia, C. (1982). Attentional processes in alcohol-mediated aggression. Journal of Studies on Alcohol, 43, 714-724. 